\title{
Chemical, Thermal, and Rheological Performance of Asphalt Binder Containing Plastic Waste
}

\author{
Rosa Veropalumbo $^{1}\left(\mathbb{D}\right.$, Francesca Russo ${ }^{1}$, Cristina Oreto ${ }^{1} \oplus$, Giovanna Giuliana Buonocore ${ }^{2}$, \\ Letizia Verdolotti $^{2, *}{ }^{\mathbb{D}}$, Herminio Muiambo ${ }^{3}$, Salvatore Antonio Biancardo ${ }^{1}(\mathbb{D})$ and Nunzio Viscione ${ }^{1}(\mathbb{D}$ \\ 1 Department of Civil, Construction and Environmental Engineering, Federico II University of Naples, \\ Via Claudio 21, 80125 Naples, Italy; rosa.veropalumbo@unina.it (R.V.); francesca.russo2@unina.it (F.R.); \\ cristina.oreto@unina.it (C.O.); salvatoreantonio.biancardo@unina.it (S.A.B.); nunzio.viscione@unina.it (N.V.) \\ 2 Institute of Composites, Polymers and Biomaterials, National Research Council, P.le E. Fermi, 1, \\ 80055 Naples, Italy; giovannagiuliana.buonocore@cnr.it \\ 3 Chemistry Department, Eduardo Mondlane University, Maputo P.O. Box 257, Mozambique; \\ hmuiambo@uem.mz \\ * Correspondence: letizia.verdolotti@cnr.it; Tel.: +39-081-7758839
}

Citation: Veropalumbo, R.; Russo, F.; Oreto, C.; Buonocore, G.G.; Verdolotti, L.; Muiambo, H.; Biancardo, S.A.; Viscione, N. Chemical, Thermal, and Rheological Performance of Asphalt Binder Containing Plastic Waste. Sustainability 2021, 13, 13887. https: / / doi.org/10.3390/su132413887

Academic Editors: Michael Wistuba, Di Wang, Chiara Riccardi, Libo Yan, Zhanping You, Lily Poulikakos and Ana Jiménez del Barco Carrión

Received: 26 October 2021

Accepted: 6 December 2021

Published: 15 December 2021

Publisher's Note: MDPI stays neutral with regard to jurisdictional claims in published maps and institutional affiliations.

Copyright: (c) 2021 by the authors. Licensee MDPI, Basel, Switzerland. This article is an open access article distributed under the terms and conditions of the Creative Commons Attribution (CC BY) license (https:// creativecommons.org/licenses/by/ $4.0 /)$.

\begin{abstract}
In order to meet the environmental needs caused by large plastic waste accumulation, in the road construction sector, an effort is being made to integrate plastic waste with the function of polymer into asphalt mixtures; with the purpose of improving the mechanical performance of the pavement layers. This study focuses on the effect of a recycled mixture of plastic waste on the chemical, thermal, and rheological properties of designed asphalt blends and on the identification of the most suitable composition blend to be proposed for making asphalt mixture through a dry modification method. Thermo-gravimetric analysis, differential scanning calorimetry, and Fourier transform infrared spectroscopy analysis were carried out to investigate the effect of various concentrations and dimensions of plastic waste (PW) on the neat binder (NB). The frequency sweep test and the multiple stress creep and recovery test were performed to analyze the viscoelastic behavior of the asphalt blends made up of PW in comparison with NB and a commercial modified bitumen (MB). It has been observed that the presence of various types of plastic materials having different melting temperatures does not allow a total melting of PW powder at the mixing temperatures. However, the addition of PW in the asphalt blend significantly improved the aging resistance without affecting the oxidation process of the plastic compound present in the asphalt blend. Furthermore, when the asphalt blend mixed with $20 \%$ PW by the weight of bitumen is adopted into the asphalt mixture as polymer, it improves the elasticity and strengthens the mixture better than the mixture containing MB.
\end{abstract}

Keywords: plastic waste; recycled asphalt blends; rheological analysis; asphalt mixture; FTIR; differential scanning calorimetry

\section{Introduction}

The global plastics economy is mainly linear: plastics are produced, used, and generally disposed of with no recovery. In order to preserve the environment while meeting consumption demands, a global effort to shift the linear economy into a circular model must be made [1,2]. A circular economy model suggests the promotion and revalorization of plastics already in circulation [3]. To date one of the main environmental problems is pollution due to plastic waste: it degrades in a very long time and consequently ends up filling beaches, seas, and other natural places, when not correctly recycled or reused. Indeed, the COVID-19 pandemic has highlighted the need for single-use plastics since potential health risks and societal fears concerning virus-contaminated products introduce consumer fears of reuse [3]. Nevertheless, these socio-material challenges need a systematic approach to plastic waste management. On this basis, the sector of asphalt pavement construction has provided a good opportunity to recycle, reuse, and reduce plastic waste. 
For this reason, many researchers in the road construction sector are investigating the reuse of plastics/polymers into bituminous mixtures [4]. The employment of polymers as bitumen modifiers has been generally studied for decades. Polymer modification of bitumen is already practiced by the asphalt industry with the aim to improve the properties related to road pavement resistance. Indeed, it has been proved that the addition of polymer into binder enhances its stiffness at high temperature, its moisture resistance, and its fatigue life [5].

Some authors have shown that using a $4.5 \%$ of SBS polymer with high-vinyl content by weight of the binder increase the number of fatigue cycles to failure when compared to a commercial polymer-modified bitumen and a virgin bitumen at any strain level [6]. Furthermore, it was found that the modification of neat bitumen using a hybrid combination of styrene-ethylene/propylene-styrene (SEPS) and montmorillonite (MMT) clay improves not only its performance at high temperature but also the aging resistance due to a lower increase in carbonyl functional groups when exposed to oxidation [7].

As a consequence of the massive plastic waste that is generated worldwide, the use of waste plastics/polymers has been also investigated. According to Wu and Montalvo [8] and Vargas and Hanandeh [9], the major types of waste polymers used to modify bitumens are polyethylene teraphthalate (PET) [10,11], which not only reduced the amount of binder required for the optimization of an asphalt mixture but also produced a significant decrease in plastic deformations; high-density polyethylene (HDPE) [12], whose optimum content between 6 and 10\% was found to improve the fatigue phenomenon where the number of loading cycles increases; polyvinyl chloride (PVC) [13], which increases the strength and stability of the mix; low-density polyethylene (LDPE) [14-16], which has been found to play important roles in asphalt's low-temperature properties and hot storage stability; polypropylene (PP) [17], which produced increases of viscosity, softening point, flash point, and the decreasing of density when added to a commercial neat bitumen, penetration, and solubility, and polystyrene (PS) [18] that can be reduced $1 \%$ of bitumen in mixture replacing it producing an extra-rigidity on the final asphalt mixture. Other polymers that are attracting researchers' attention are ethylene-vinyl acetate (EVA) [19-21], polyurethane (PU) [22-24], acrylonitrile butadiene styrene (ABS) [25], and polycarbonate [26].

Among the waste plastic polymers, polyethylene (PE) is considered the most effective for bitumen modification $[27,28]$.

For example, Padhan and Sreeram [29] evaluated the effect of adding PE into a neat commercial-grade VG 10 binder with a 2:1 ratio to modify it. Better performances were obtained, in particular, the addition of PE exhibited higher softening point and rotational viscosity values, and lower penetration values than the neat binder.

Kakar et al. [30] showed that the addition of 5\% PE by mass to the binder lead to an increase in the resistance to the rutting with respect to commercial polymer-modified binders.

Brasiliero et al. [31] analyzed the feasibility of using two percentages (6.5 and 12.5\% by the weight of binder) of flakes made from recycled PE as binder modifiers. It was found that as the amount of PE increases the binder shows similar properties of a modified binder manufactured in the refinery, leading to an increase of the complex modulus and at the same time a reduction of the phase angle at high temperature.

Some studies were focused on the effect of mixing high-density polyethylene (HDPE) (melting point at $180{ }^{\circ} \mathrm{C}$ ), low-density polyethylene (LDPE) (melting point at $160{ }^{\circ} \mathrm{C}$ ), and polypropylene (PP) (melting point at $190^{\circ} \mathrm{C}$ ) on the viscoelastic performance of a traditional binder [32]. It has been shown that the addition of LDPE at loading above $2 \%$ by the weight of binder increase the viscoelastic behavior of the bitumen [33] while the addition of PE at loading between $2 \%$ and $8 \%$ by the weight of the binder [34] improves the fatigue performance of the binder with an increase of the failure values (Nf).

Nizamuddin et al. [5] reported that the addition of recycled LDPE as a modifier for bitumen showed significant improvements in the physical, chemical, rheological and thermal properties of base bitumen. Specifically, a concentration between 3 and $6 \%$ by the weight of bitumen is suggested to enhance sustainability and increase performance, thus 
favoring its use during construction. Other researchers have studied different plastic waste blends to find the optimum compositions for pavements that could withstand heavily loaded vehicles and hot climates. Particularly, several studies have been conducted on the reuse of PET widely used in the production of beverage containers and polyester textiles [35]. Merkel et al. [35] showed that additives made from deconstructed PET wastes, chemically modified through aminolysis to obtain terephthalic amides, improve the performance properties of asphalt at various experimental conditions.

It has already been proven that the mixtures containing waste plastic bottles have lower optimum asphalt content compared to the conventional mixture, which could reduce the amount of asphalt binder used in road construction [36]. When plastic wastes are used as modifiers into asphalt mixtures [37], the performance properties of the asphalt mixture are enhanced, in particular, the mixture turns to be less sensitive to moisture damage.

Given the above scenario, the aim of the present research is to investigate the effect of various concentrations and dimensions of plastic waste (PW), mainly composed of a mixture of PET and PE, on the structural, thermal, and rheological properties of asphalt blends, and, in a preliminary analysis, the feasibility to introduce PW into asphalt mixture through a dry method, to obtain performance similar to those of mixture containing commercial modified bitumen. A series of tests have been carried out as synthetized in the experimental program shown in Figure 1. The first phase of the research deals with the investigation of the main properties of the materials that are adopted for making the asphalt blends, and the asphalt mixtures, i.e., neat bitumen (NB) 50/70 penetration grade, modified bitumen 10/40-70 (MB), plastic waste, and limestone aggregates. After that, the asphalt blends containing PW were prepared, and jointly the basic properties in terms of ring and ball (EN 1427 [38]) and viscosity (EN 13702 [39]) were analyzed. Chemical characterization and a thermal degradation analysis were carried out on the asphalt blends to explore the effect of $\mathrm{PW}$ when mixed at a high temperature of $150{ }^{\circ} \mathrm{C}$ with NB. Subsequently, the main rheological properties were assessed, including the two binders (NB and $\mathrm{MB}$ ), by means of a dynamic shear rheometer (DSR) and performing a frequency sweep (FS) test (EN 14770 [40]) and a multiple stress creep and recovery (MSCR) test (EN 16659 [41]). After the identification of the most suitable asphalt blend with PW among those analyzed, the same amount of PW corresponding to this blend was used for the preparation of an asphalt mixture optimized according to the Superpave procedures through the dry method, in compliance with the same volumetric properties of a traditional hot mix asphalt with NB and a hot mix asphalt prepared with $\mathrm{MB}$, used as control mixes. On the three obtained mixtures, the indirect tensile strength (EN 12697-23 [42]) and the moisture damage (EN 12697-12 [43]) tests were performed to investigate the effect of PW within an asphalt mixture. 


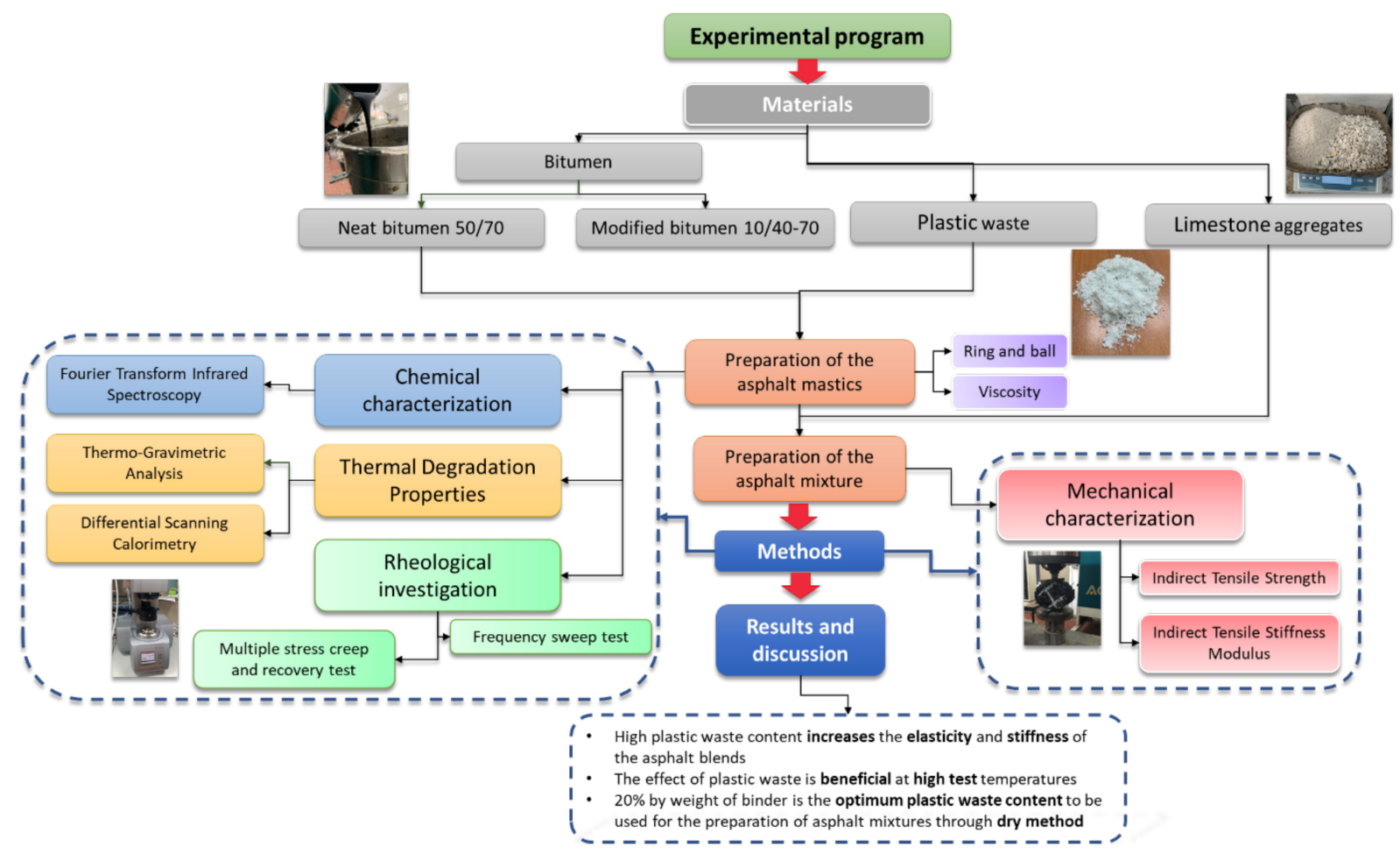

Figure 1. Summary of the experimental program.

\section{Materials and Methods}

\subsection{Materials}

2.1.1. Binders

The neat bitumen (NB), 50/70 penetration grade, was obtained from an oil refinery in Southern Italy. The blends were prepared using NB while a modified bitumen 10/40-70 (MB) was used as a control binder. Table 1 gives a summary of the results of some tests performed on the two bitumens.

Table 1. Bitumen basic properties.

\begin{tabular}{ccccc}
\hline Properties & \multirow{2}{*}{ Unit } & Standard & NB & MB \\
\hline Penetration at $25^{\circ} \mathrm{C}$ & $\mathrm{dmm}$ & $\mathrm{EN} \mathrm{1426} \mathrm{[44]}$ & 68 & 52 \\
Softening point $(\mathrm{R} \& \mathrm{~B})$ & ${ }^{\circ} \mathrm{C}$ & $\mathrm{EN} \mathrm{1427} \mathrm{[38]}$ & 46 & 87 \\
Dynamic viscosity at $135^{\circ} \mathrm{C}$ & & & 0.25 & 1.38 \\
Dynamic viscosity at $100^{\circ} \mathrm{C}$ & $\mathrm{Pa} \mathrm{s}$ & $\mathrm{EN} \mathrm{13702} \mathrm{[39]}$ & 4.10 & 9.18 \\
Dynamic viscosity at $60^{\circ} \mathrm{C}$ & & & 185 & 1560 \\
\hline
\end{tabular}

\subsubsection{Plastic Waste}

The plastic waste (PW) used as a modifier was obtained from the mechanical shredding of plastic bottles and made up of different plastic waste types, PET, HDPE, LDPE, and PE (see Figure 2a). The shredded plastic was washed and then dried by centrifugation and airstream ventilation for the removal of non-plastic residual material. The final size was obtained by an extruder equipped with a series of perforated plates whose diameter range from 4 to $0.125 \mathrm{~mm}$. 


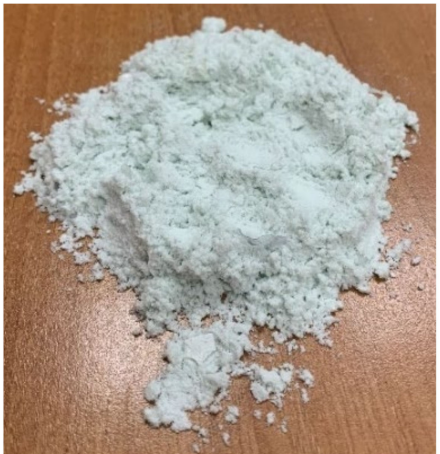

(a)

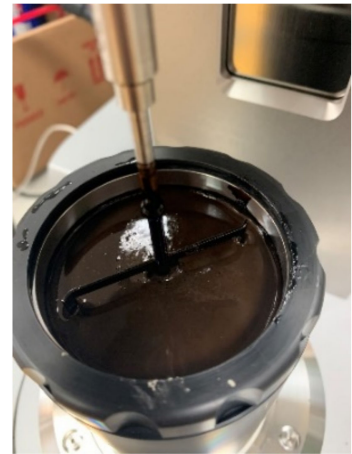

(b)

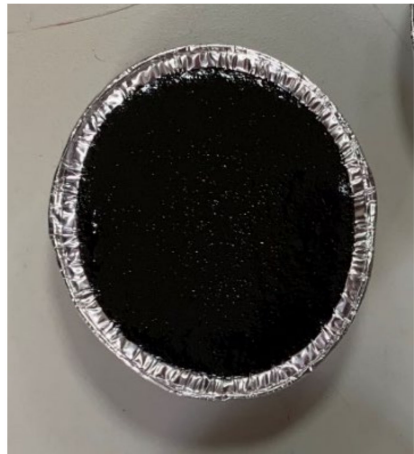

(c)

Figure 2. Blend preparation: (a) plastic waste powder with a size between 4 and $0.063 \mathrm{~mm}$; (b) mixing phase; (c) final blend.

\subsubsection{Preparation of the Bituminous Blends}

Two different samples of PW were adopted to obtain the modified bituminous blends: (a) PW with size/diameter ranging from $4 \mathrm{~mm}$ to $0.063 \mathrm{~mm}$, and (b) PW with size/diameter ranging from $4 \mathrm{~mm}$ to $0.25 \mathrm{~mm}$.

Therefore, three bituminous blends were prepared as follows:

- NB mixed with $10 \%$ PW by the weight of NB whose size ranges between 4 and $0.25 \mathrm{~mm}$, (B1).

- $\quad$ NB mixed with $10 \%$ PW by the weight of NB whose size ranges between 4 and $0.063 \mathrm{~mm}$, (B2).

- NB mixed with $20 \%$ PW by the weight of NB whose size ranges between 4 and $0.063 \mathrm{~mm}$, (B3).

An asphalt blend with NB plus $20 \%$ PW by the weight of NB whose size ranges between 4 and $0.25 \mathrm{~mm}$ was not studied, since the obtained compound was not workable.

The blend preparation consisted of the following steps [45]: first of all, the bitumen was preheated in a metal container at $150{ }^{\circ} \mathrm{C}$ for $1 \mathrm{~h}$, and then poured into a steel container previously oven heated to $150{ }^{\circ} \mathrm{C}$. A known amount of PW was slowly added to the bitumen and then mixed in the mixer at $4500 \mathrm{rpm}$ speed for approximately $10 \mathrm{~min}$ (see Figure $2 b$ ), until a homogeneous compound was reached (see Figure 2c).

A preliminary analysis was made in terms of ring and ball (R\&B) by comparing NB with the obtained three mixtures (B1, B2, and B3) to assess the effect derived from the addition of PW. As can be seen from the results reported in Table 2, R\&B values of B1, B2, and B3 samples have been improved by 23, 20, and 88\%, respectively, in comparison with NB.

Table 2. Basic properties of studied materials: ring and ball and viscosity at $100{ }^{\circ} \mathrm{C}$ and $135^{\circ} \mathrm{C}$.

\begin{tabular}{cccc}
\hline Sample & $\begin{array}{c}\mathbf{R} \& \mathbf{B} \\
\left({ }^{\circ} \mathbf{C}\right)\end{array}$ & $\begin{array}{c}\text { Viscosity at } \mathbf{1 0 0}{ }^{\circ} \mathbf{C} \\
\mathbf{( P a} \times \mathbf{s})\end{array}$ & $\begin{array}{c}\text { Viscosity at } \mathbf{1 3 5}{ }^{\circ} \mathbf{C} \\
\mathbf{( P a} \times \mathbf{s})\end{array}$ \\
\hline MB & 87.0 & 9.18 & 1.38 \\
NB & 46.0 & 4.10 & 0.25 \\
B1 & 56.8 & 19.73 & 1.56 \\
B2 & 55.2 & 8.83 & 4.93 \\
B3 & 86.3 & 15.62 & 2.45 \\
\hline
\end{tabular}

As expected, the viscosity values (see Table 2) of the three blends B1, B2, and B3 are higher than those of NB, at both $100{ }^{\circ} \mathrm{C}$ and $135^{\circ} \mathrm{C}$. In particular, at $100{ }^{\circ} \mathrm{C}$, the lowest increase $(115 \%)$ was shown by the B2 sample while the highest (381\%) was obtained by the B1 sample, while at $135{ }^{\circ} \mathrm{C}$ keeping constant the PW amount at 10\%, B1 shows a lower viscosity value $(68 \%)$ compared to $\mathrm{B} 2$. 
It is worth noting that, both at $100{ }^{\circ} \mathrm{C}$ and $135^{\circ} \mathrm{C}$, the $10 \% \mathrm{PW}$ blends show viscoelastic properties similar to the MB sample, in particular, the B2 sample at $100{ }^{\circ} \mathrm{C}$ and the B1 sample at $135^{\circ} \mathrm{C}$.

It is noticeable from the above results that the increase of the PW content with a narrower size range gives rise to blends more sensitive to the temperature and, therefore, more workable during the blending operation at temperatures around $150{ }^{\circ} \mathrm{C}$.

\subsubsection{Grading Curve with Limestone Aggregates}

An asphalt concrete (AC) grading curve with a maximum size of $20 \mathrm{~mm}$ (AC20) for a binder layer was designed in this study by adopting four different sizes of limestone aggregates provided by a local quarry in southern Italy; Table 3 shows the mechanical and volumetric properties (apparent specific gravity (Gsa) and bulk specific gravity (Gsb)) of the limestone aggregates.

Table 3. Aggregate main properties.

\begin{tabular}{|c|c|c|c|c|c|c|}
\hline & $\begin{array}{c}\text { Los Angeles } \\
\text { (\%) } \\
\text { EN 1097-2 [46] }\end{array}$ & $\begin{array}{c}\text { Shape Index } \\
(\%) \\
\text { EN 933-4 [47] }\end{array}$ & $\begin{array}{c}\begin{array}{c}\text { Flat Index } \\
(\%)\end{array} \\
\text { EN 933-3 [48] }\end{array}$ & $\begin{array}{c}\text { Sand } \\
\text { Equivalent } \\
(\%) \\
\text { EN 933-8 [49] }\end{array}$ & $\begin{array}{c}\text { Gsa } \\
\left(\mathrm{g} / \mathrm{cm}^{3}\right) \\
\text { EN 1097-6 [50] }\end{array}$ & $\begin{array}{c}\text { Gsb } \\
\left(\mathrm{g} / \mathrm{cm}^{3}\right) \\
\text { EN 1097-6 [51] }\end{array}$ \\
\hline \multicolumn{7}{|c|}{ Coarse aggregate } \\
\hline $\begin{array}{l}\text { Limestone } \\
10 / 18\end{array}$ & 20.6 & 4 & 8 & n.d. * & 2.694 & 2.686 \\
\hline Limestone 6/12 & 20.1 & 8 & 11 & n.d. & 2.713 & 2.687 \\
\hline \multicolumn{7}{|c|}{ Fine aggregate } \\
\hline Limestone sand & n.d. & n.d. & n.d. & 95.3 & 2.718 & 2.679 \\
\hline Limestone filler & n.d. & n.d. & n.d. & n.d. & 2.737 & 2.737 \\
\hline
\end{tabular}

The design of the grading curve was defined according to the following requirements:

- $\quad$ EN 13108-1 [51] (see Table 1 in EN 13108-1);

- Special tender documents of southern Italy for a binder layer;

- Superpave requirements, according to the control points, defined for a nominal maximum aggregate size of $19 \mathrm{~mm}$, and a sand restricted zone to be avoided for compatibility problems [52];

- Maximum-density gradation, according to the Fuller and Thompson equation, to be avoided $(\mathrm{n}=0.45)$ [53].

The obtained design curve is reported in Figure 3.

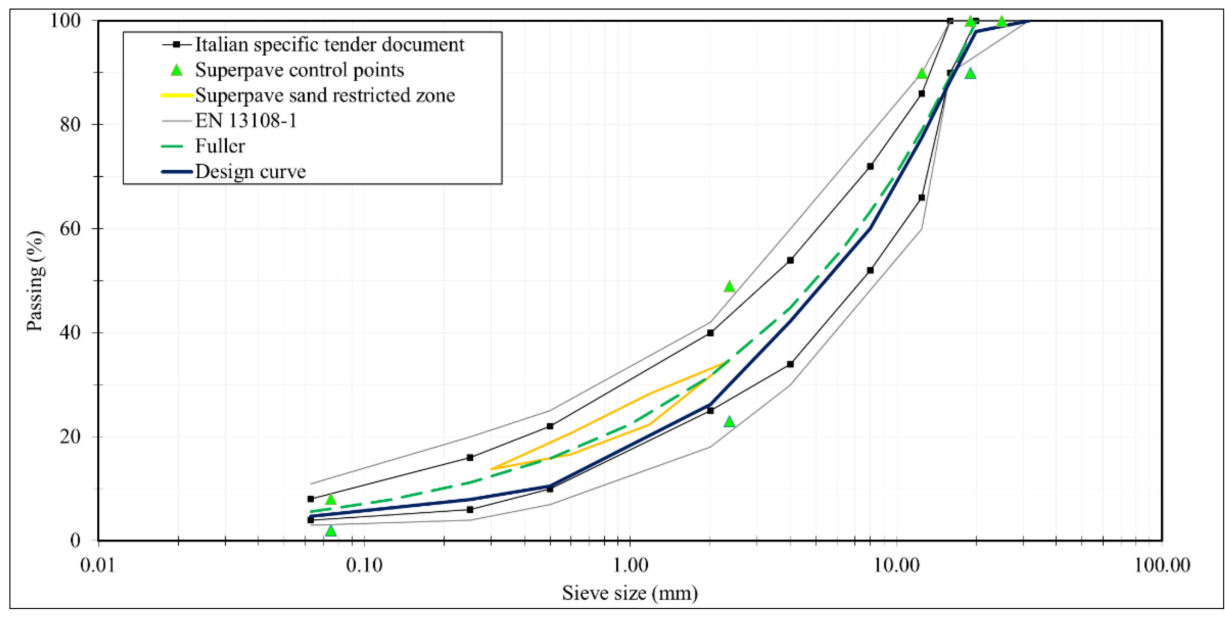

Figure 3. Grading curve for the binder layer. 


\subsubsection{Mix Design}

According to the purpose of the study, to carry out the analysis on the asphalt mixture when PW is added using the dry method, it was necessary to optimize, in the first analysis, a hot mix asphalt with $\mathrm{NB}\left(\mathrm{HMA}_{\mathrm{NB}}\right)$ and a hot mix asphalt made up of $\mathrm{MB}\left(\mathrm{HMA}_{\mathrm{MB}}\right)$, with the same volumetric properties [54]. The Superpave protocol was followed for the mix design phase, adopting a gyratory compactor to make cylindrical specimens (see Figure 4b) in compliance with EN 12697-31 [55].

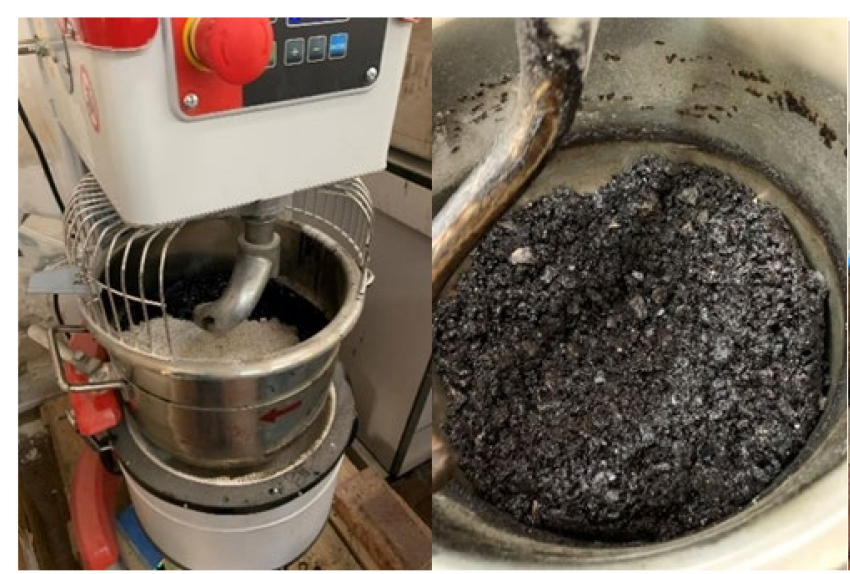

(a)

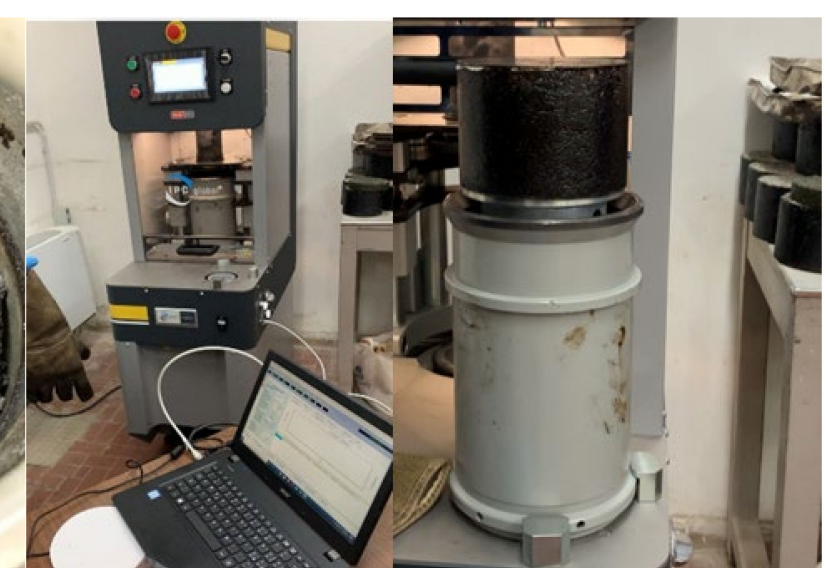

(b)

Figure 4. (a) Asphalt mixing phase and (b) gyratory compaction.

The mixing procedure adopted to define the optimum binder content $(\mathrm{OBC})$ for both $\mathrm{HMA}_{\mathrm{NB}}$ and $\mathrm{HMA}_{\mathrm{MB}}$ was as follows:

- The aggregates were oven heated at $180^{\circ} \mathrm{C}$, and since NB and MB showed different viscosity values (see Section 2.1.3) and therefore required different mixing temperatures, $\mathrm{NB}$, and $\mathrm{MB}$ were preheated respectively at 150 and $185^{\circ} \mathrm{C}$.

- The coarse aggregates and sand were blended with the bitumen for $4 \mathrm{~min}$ at the mixing temperature depending on binder type, after that the filler was added and the mixing continued for others $5 \mathrm{~min}$ (see Figure 4a).

After the mixing phase, the mixture was put in the oven for $2 \mathrm{~h}$ to reach a uniformity compaction temperature of 150 and $175^{\circ} \mathrm{C}$ for $\mathrm{HMA}_{\mathrm{NB}}$ and $\mathrm{HMA}_{\mathrm{PMB}}$, respectively. To satisfy the Superpave requirement for a Va equal to $4 \%$ at Ndes, 100 and 112 were found to be the appropriate Ndes for $\mathrm{HMA}_{\mathrm{NB}}$ and $\mathrm{HMA}_{\mathrm{MB}}$ respectively. The results of the mix design are shown in Table 4.

Table 4. Superpave optimization: $\mathrm{HMA}_{\mathrm{NB}}$ vs. $\mathrm{HMA}_{\mathrm{PMB}}$ volumetric properties.

\begin{tabular}{lccccc}
\hline Mixture & $\begin{array}{c}\mathbf{V}_{\mathbf{a}} \\
(\mathbf{\%})\end{array}$ & $\begin{array}{c}\text { VMA } \\
\mathbf{( \% )}\end{array}$ & $\begin{array}{c}\text { VFA } \\
\mathbf{( \% )}\end{array}$ & $\begin{array}{c}\mathbf{\%}_{\mathbf{m m}} \text { at } \\
\mathbf{( \% )}\end{array}$ & $\begin{array}{c}\text { Dust Portion } \\
(\mathbf{- )}\end{array}$ \\
\hline $\mathrm{HMA}_{\mathrm{NB}}$ & 4.0 & 14.2 & 70.6 & $85.57 \%$ & 1.1 \\
$\mathrm{HMA}_{\mathrm{MB}}$ & 4.1 & 14.4 & 71.8 & $95.90 \%$ & 1.1 \\
\hline
\end{tabular}

\subsection{Methods}

\subsubsection{Chemical Characterization: Fourier Transform Infrared Spectroscopy-FTIR}

FTIR spectra were recorded at room temperature by using an infrared spectrometer (model Frontier Dual Ranger, PerkinElmer, Waltham, MA, USA) in attenuated total reflectance (ATR) mode from 650 to $4000 \mathrm{~cm}^{-1}$ [2,56]. Spectra were recorded at $4 \mathrm{~cm}^{-1}$ resolutions and reported the average of 64 scans. It has been proved by several researchers [57] that infrared spectroscopy (FTIR) in ATR mode is an efficient and reliable method to investigate and monitor the chemical arrangement (i.e., oxidative phenomena) and structure of 
asphalt samples. Hence, it has been used to analyze NB, its composite samples, B1, B2, B3, and MB.

In the region ranging from 2000 to $600 \mathrm{~cm}^{-1}$, the main vibration peaks, which are indicators of asphalt binder oxidation level, absorb namely carbonyl $(\mathrm{C}=\mathrm{O}$, around 1700 to $\left.1740 \mathrm{~cm}^{-1}\right)$, sulfoxide functional groups $\left(\mathrm{S}=\mathrm{O}\right.$, around $\left.1030 \mathrm{~cm}^{-1}\right)$, along with butadiene $\left(-\mathrm{CH}=\mathrm{CH}-, 960 \mathrm{~cm}^{-1}\right)$ and styrene (aromatic groups, around $\left.690-750 \mathrm{~cm}^{-1}\right)$ peaks [2].

In order to better understand the influence of PW filler on the chemistry of bitumen, we performed the FTIR characterization of the "neat" PW and of the PW after thermal treatment at $150{ }^{\circ} \mathrm{C}$, which represents the average temperature used for the preparation of bitumen composites. All the spectra were baseline corrected by using Perkin Elmer Spectrum software.

\subsubsection{Thermal Degradation Properties (TGA and DSC)}

The thermal degradation behavior was evaluated by thermo-gravimetric analysis (TGA) and differential scanning calorimetry (DSC). TGA was carried out in air and in nitrogen flow (flow rate $=40 \mathrm{~mL} / \mathrm{min}$ ) using a TGAQ500 TA instrument, at a heating rate of $10^{\circ} \mathrm{C} / \mathrm{min}$ in the temperature range from $30^{\circ} \mathrm{C}$ to $1000{ }^{\circ} \mathrm{C}$, with sample mass of approximately $10 \mathrm{mg}[58,59]$.

DSC analyses were conducted on Q1000 TA instruments. Samples were first heated from $-80{ }^{\circ} \mathrm{C}$ to $200{ }^{\circ} \mathrm{C}$ and then subjected to cooling up to $-80^{\circ} \mathrm{C}$, and finally reheated to $200{ }^{\circ} \mathrm{C}$. The rates of heating and cooling were $10^{\circ} \mathrm{C} / \mathrm{min}$.

\subsubsection{Properties Investigation of Asphalt Binders and Mixtures}

The rheological investigation of the asphalt binders was carried out by means of the frequency sweep (FS) test (EN 14770 [40]) and multiple stress creep and recovery (MSCR) test (EN 16659 [41]).

The FS test was carried out using frequency values falling within a range from 0.1 to $10 \mathrm{~Hz}$ (a total of 20 observations were made with a gap of 0.1 for frequencies from 0.1 to $1 \mathrm{~Hz}$, and a gap of $1 \mathrm{~Hz}$ for frequencies from 1 to $10 \mathrm{~Hz}$, passing through $1.59 \mathrm{~Hz}$ ) at six test temperatures $\left(0,10,20,30,40\right.$, and $50^{\circ} \mathrm{C}$ ). A Dynamic Shear Rheometer (DSR, Anton Paar Smart PAVE 102 type) was used.

A "25 mm plate-plate geometry" with a $1 \mathrm{~mm}$ gap was adopted to carry out the rheological analysis at test temperatures above $30^{\circ} \mathrm{C}$, and an " $8 \mathrm{~mm}$ plate-plate geometry" with a $2 \mathrm{~mm}$ gap as the DSR configuration was used to investigate all the specimens at test temperatures below $30^{\circ} \mathrm{C}$.

The ratio between the maximum shear stress $\left(\tau_{\max }\right)$ and the maximum shear strain $\left(\gamma_{\max }\right)$ determined the complex shear modulus $\left(\left|G^{*}\right|\right)$ (see Equations (1) and (2)), while the lag between $\tau_{\max }$ and $\gamma_{\max }$ obtained the phase angle $(\delta)$.

$$
\begin{gathered}
\left|G^{*}\right|=\frac{\tau_{\max }}{\gamma_{\max }} \\
\left|G^{*}\right|=\sqrt{G^{\prime 2}+G^{\prime \prime 2}}=\left|G^{*}\right| \cdot \cos \varphi+\left|G^{*}\right| \cdot \operatorname{sen} \varphi
\end{gathered}
$$

where $G^{\prime}$ is the storage modulus and $G^{\prime \prime}$ is the loss modulus, both in $\mathrm{kPa}$.

The MSCR test was carried out using DSR. Non-recoverable creep compliance (Jnr), which is one of the parameters that give a measure of the degree of resistance of a bituminous mastic and/or binder to permanent deformations under repeated loading-unloading cycles was established in accordance with EN 16659 [41]: two stress levels of $0.1 \mathrm{kPa}$ and $3.2 \mathrm{kPa}$, and two test temperatures $\left(40\right.$ and $\left.50{ }^{\circ} \mathrm{C}\right)$ were used.

The mean value of non-recoverable creep compliance at the $N$-th cycle $\left(J_{n r}^{N}\right.$, see Equation (3)) and the mean value of the total creep compliance at the $N$-th cycle $\left(J_{t o t}^{N}\right.$, see Equation (4)) over ten cycles of creep and recovery was calculated for each temperature under 0.1 and $3.2 \mathrm{kPa}$.

$$
J_{n r}^{N}=\varepsilon_{10}^{N} / \tau \quad\left(\mathrm{kPa}^{-1}\right)
$$




$$
J_{t o t}^{N}=\varepsilon_{1}^{N} / \tau \quad\left(\mathrm{kPa}^{-1}\right)
$$

where $\varepsilon_{10}^{N}$ is the strain value at the end of the recovery phase (after $10 \mathrm{~s}$ ) of the $N$-th cycle, $\tau$ is the applied stress, $0.1 \mathrm{kPa}$ and $3.2 \mathrm{kPa}$ and $\varepsilon_{1}^{N}$ is the strain value at the end of the creep phase (after $1 \mathrm{~s}$ ) of the $N$-th cycle.

The indirect tensile strength (ITS) and the indirect tensile stiffness modulus (ITSM) were adopted for the mechanical characterization of the asphalt mixtures.

The ITS was carried out according to EN 12697-23 [42]. The cylindrical specimen to be tested is brought to the specified test temperature of $10{ }^{\circ} \mathrm{C}$, placed in the compression testing machine between the loading strips, and loaded diametrically along the direction of the cylinder axis with a constant speed of displacement until it breaks. The ITS is the maximum tensile stress calculated from the peak load applied at break and the dimensions of the specimen, calculated by using Equation (5).

$$
I T S=\frac{2 P}{\pi D H}
$$

where ITS is the indirect tensile strength $(\mathrm{GPa}), P$ is the peak load $(\mathrm{kN}), D$ is the diameter of the specimen $(\mathrm{mm})$, and $H$ is the height of the specimen $(\mathrm{mm})$.

A total of three specimens were tested and the final ITS value was obtained as a mean value of the three determinations.

The stiffness modulus conducted at three different temperatures of 10,20 , and $40{ }^{\circ} \mathrm{C}$ was calculated using an indirect tensile load configuration, in compliance with ANNEX C of the EN 12697-26. Since the standard requires that the peak load value shall be adjusted to achieve a target peak transient horizontal deformation of $0.005 \%$ of the specimen diameter when the test temperature is $10{ }^{\circ} \mathrm{C}$, the test was conducted under strain control to keep constant the strain level below $50 \mu \varepsilon$ for each temperature. The ITSM was calculated using Equation (6).

$$
I T M=\frac{F \times(v+0.27)}{z \times h}
$$

where $F$ is the peak value of the applied vertical load $(N), z$ is the amplitude of the horizontal deformation obtained during the load cycle $(\mathrm{mm}), h$ is the mean thickness of the specimen $(\mathrm{mm})$, and $v$ is Poisson's ratio (assumed to be 0.35 ).

\section{Results and Discussion}

\subsection{FTIR Characterization}

In order to better understand the role of PW in the development of bituminous composites and on their chemistry, the FTIR characterization of "neat" PW and of PW after thermal treatment at $150{ }^{\circ} \mathrm{C}$, which represents the processing temperature for the production of bitumen composites, has been performed. From the analysis of the FTIR spectra related to the PW powders before and after the thermal treatment (see Figure 5), the main characteristic absorption peaks correlated to the various plastic materials contained in the PW (PET, HDPE, LDPE, PP) have been identified. For instance, the C-H stretching vibration absorption, in the range $2964-2910 \mathrm{~cm}^{-1}$, which is from a bond uniquely identified in polymeric materials, along with the stretching vibrations of $\mathrm{C}-\mathrm{C}$ and $\mathrm{C}-\mathrm{O}-\mathrm{C}$ bonds around $1016 \mathrm{~cm}^{-1}$ and $1100 \mathrm{~cm}^{-1}$ and the bending vibrations of $\mathrm{CH}_{2}$ at $1293 \mathrm{~cm}^{-3}$ were identified. Yet, the specific $\mathrm{C}=\mathrm{O}$ (carbonyl functional group) vibration peaks, mainly related to the abundant presence of polyesters in the investigated PW, such as PET, were identified at around $1716 \mathrm{~cm}^{-1}$. Moreover, a further sharp peak at $3435 \mathrm{~cm}^{-1}$ was ascribed to the O-H and/or N-H stretching vibrations, attributed to the hydrolytic and oxidizing processes occurring on the surface of the PW $[2,60]$. The comparison of the spectra before (green curve) and after (red curve) the thermal treatment at $150{ }^{\circ} \mathrm{C}$ also shows an increase in the intensity of the carbonyl absorption group $(\mathrm{C}=\mathrm{O})$ in the thermally treated sample. This is mainly due to the oxidation of polyolefins (LDPE, HDPE, PP) exposed at high temperatures $[2,60]$. 


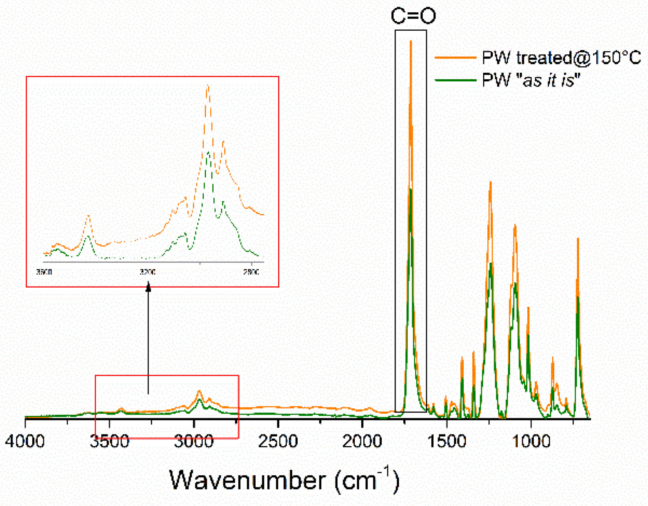

(a)

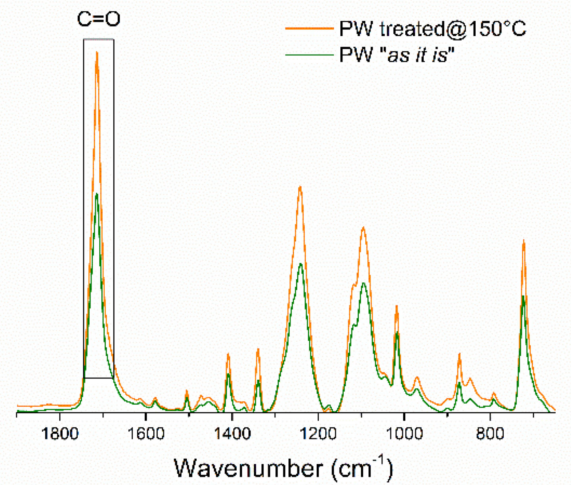

(b)

Figure 5. FTIR spectra of plastic waste, before and after thermal treatment at $150{ }^{\circ} \mathrm{C}$ (a) complete investigation range (b) magnification in the range 700-1900.

Figure 6 reports the FTIR spectra of neat and composite bitumen samples (MB, NB, B1, B2, and B3), and Table 5 summarizes the main vibrational assignments. The assignments around $2850 \mathrm{~cm}^{-1}$ and $2920 \mathrm{~cm}^{-1}$ were ascribed to the stretching vibrations of the aliphatic $\mathrm{C}-\mathrm{H}$ bonds and the corresponding bending vibrations were identified at $1460 \mathrm{~cm}^{-1}$. Additionally, the $\mathrm{C}=\mathrm{C}$ ring vibration bands from aromatic species were recorded at around $1605-1590 \mathrm{~cm}^{-1}$.

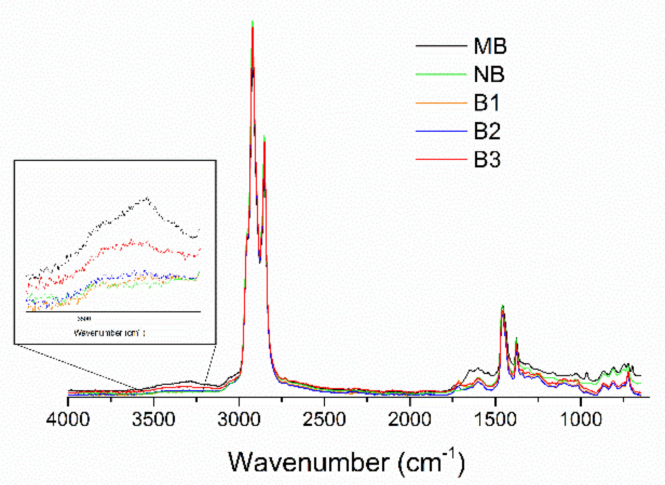

(a)

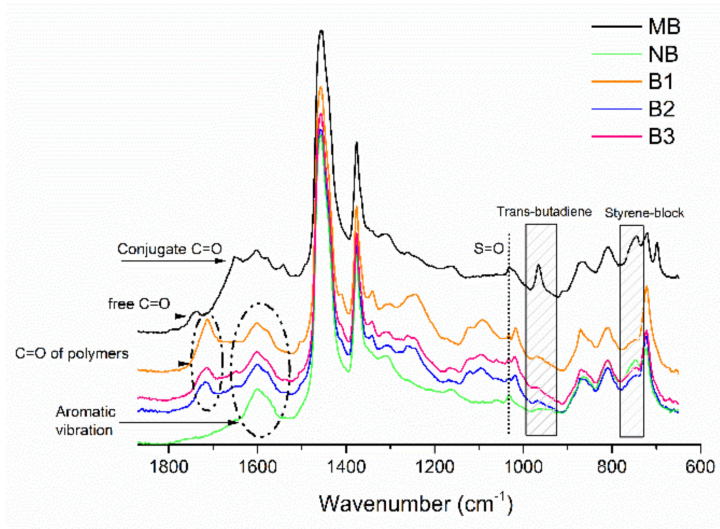

(b)

Figure 6. FTIR spectra of MB, NB, B1, B2, and B3 bitumen samples (a) all ranges; (b) range between 1800 and $600 \mathrm{~cm}^{-1}$.

Table 5. Assignments of the main IR bands of bitumen samples and their composites.

\begin{tabular}{|c|c|c|c|c|c|c|}
\hline \multirow{2}{*}{ Assignment } & \multirow{2}{*}{ Groups Assignment } & & & Samples & & \\
\hline & & MB & NB & B1 & $\overline{B 2}$ & B3 \\
\hline$v_{s t} \mathrm{C}-\mathrm{H}$ & Aliphatic species & 2900 & 2900 & 2900 & 2900 & 2900 \\
\hline$v_{s t} \mathrm{C}=\mathrm{O}$ & Free carbonyl & 1741 & n.d. & 1716 & 1716 & 1716 \\
\hline$v_{s t} \mathrm{C}=\mathrm{O}$ & Conjugate carbonyl & 1685 & n.d. & n.d. & n.d. & n.d. \\
\hline$v_{s t} \mathrm{C}=\mathrm{C}$ & Aromatic ring vibration & 1605 & 1601 & 1590 & 1590 & 1590 \\
\hline$\delta \mathrm{C}-\mathrm{H}$ & Methylene & 1373 & 1373 & 1373 & 1373 & 1373 \\
\hline$v_{s t} \mathrm{~S}=\mathrm{O}$ & Sufoxide & 1033 & 1030 & 1031 & 1031 & 1031 \\
\hline$v_{s t} \mathrm{C}-\mathrm{O}-\mathrm{C}$ & Ether & n.d. & n.d. & 1015 & 1015 & 1015 \\
\hline$v_{s t}-\mathrm{HC}=\mathrm{CH}-$ & Trans-butadiene block & $\sim 965$ & n.d. & $\sim 968$ & $\sim 968$ & $\sim 968$ \\
\hline$\delta \mathrm{C}-\mathrm{H}$ & Styrene block & $\sim 748$ & $\sim 748$ & $\sim 748$ & $\sim 748$ & $\sim 748$ \\
\hline$\delta \mathrm{C}=\mathrm{C}$ & Aromatic ring vibration & 813 & 815 & 815 & 815 & 815 \\
\hline
\end{tabular}


In the vibrational range $1500-1800 \mathrm{~cm}^{-1}$, MB showed some oxidized species which come from the aging of SBS moieties contained in the bitumen [57], i.e., the $\mathrm{C}=\mathrm{O}$ vibration peaks, at $1741 \mathrm{~cm}^{-1}$, are correlated to the free carbonyl, and at $1690 \mathrm{~cm}^{-1}$, are associated to the conjugate carbonyl. This vibration peak was not observed for the NB, thus indicating that the NB is not oxidized. For the samples B1, B2, and B3, the stretching vibrations of free-carbonyl group $C=O$ were recorded at lower wavenumbers, namely around $1716 \mathrm{~cm}^{-1}$. This peak can be correlated to the carbonyl stretching of PW as observed in the spectra reported in Figure 5. This means that the addition of PW in the bitumen blends does not affect the oxidation/aging process of bitumen.

Additionally, for the MB sample and for NB, a new characteristic oxidation peak at around $1030 \mathrm{~cm}^{-1}$ has been observed and identified as the $\mathrm{S}=\mathrm{O}$ bond in sulfoxide. Instead, in the case of the B1, B2, and B3 blends, in addition to the $\mathrm{S}=\mathrm{O}$ slight peak $\left(\sim 1033 \mathrm{~cm}^{-1}\right)$, a vibrational peak at $1018 \mathrm{~cm}^{-1}$, attributed to the C-O-C bond of plastic waste, was also observed (Figure 6b).

Furthermore, the vibration peaks associated with the trans-di-substituted $-\mathrm{CH}=\mathrm{CH}-$ butadiene block $\left(968 \mathrm{~cm}^{-1}\right)$ and to the $\mathrm{C}-\mathrm{H}$ aromatic mono-substituted (styrene block, at $748 \mathrm{~cm}^{-1}$ ) have been highlighted in the spectra of MB samples and NB. At the same wavenumber values, a small shoulder has been also recorded for the investigated blends (B1, B2, and B3).

Moreover, a slight band at around $3400 \mathrm{~cm}^{-1}$ (correlated to the -OH-stretching) has been observed for MB samples (mainly for B3), likely related to the oxidation of the polybutadiene portion in the copolymer.

From the discussion above, it can be concluded that the addition of PW does not affect the oxidation process of SBS-based bitumen, but its presence significantly improves the aging resistance if compared to results obtained using other fillers such the crumb rubber, as also observed by other authors [60].

\subsection{Thermal Analysis (TGA and DSC) of Neat Plastic Waste, Neat Bitumen, and Their Composites}

To better evaluate the effect of PW on the thermal behavior of composite bitumen, thermal degradation properties of neat PW through TGA (in both air and $\mathrm{N}_{2}$ atmosphere) and DSC analysis have been carried out and the results are reported in Figure 7. In particular, TGA in a N2 atmosphere of the PW sample (Figure 7a) showed a degradation step in the range $360-420{ }^{\circ} \mathrm{C}$ with an onset temperature at $361^{\circ} \mathrm{C}$, and a corresponding weight loss of about $90 \%$, that is likely related to the thermal degradation of PET. As already evidenced by FTIR analysis, DSC results (see Figure $7 \mathrm{~b}$ ) clearly show that the main component of the mixture is PET, with its typical melting temperature observed at $248{ }^{\circ} \mathrm{C}$. In addition, from TGA under air atmosphere (reported in Figure 7c) the thermogram shows three separate portions of the mass loss curve: the first one correlated to the HDPE/PP mix (around $3 \mathrm{wt} \%$ of mass loss) and the second one to the PET (around $84 \mathrm{wt} \%$ of weight loss), both degrade quickly into char and volatiles at around $150-250{ }^{\circ} \mathrm{C}$ and $377-527^{\circ} \mathrm{C}$, respectively [61]. In the third part, further increase in temperature slowly decomposed $(\sim 13 \%)$ the char, which is combusted by reacting with oxygen. From this last analysis, it is possible to assume that in the PW mixture there are $96.5 \mathrm{wt} \%$ of PET and $3.5 \mathrm{wt} \%$ of HDPE/PP mix. 

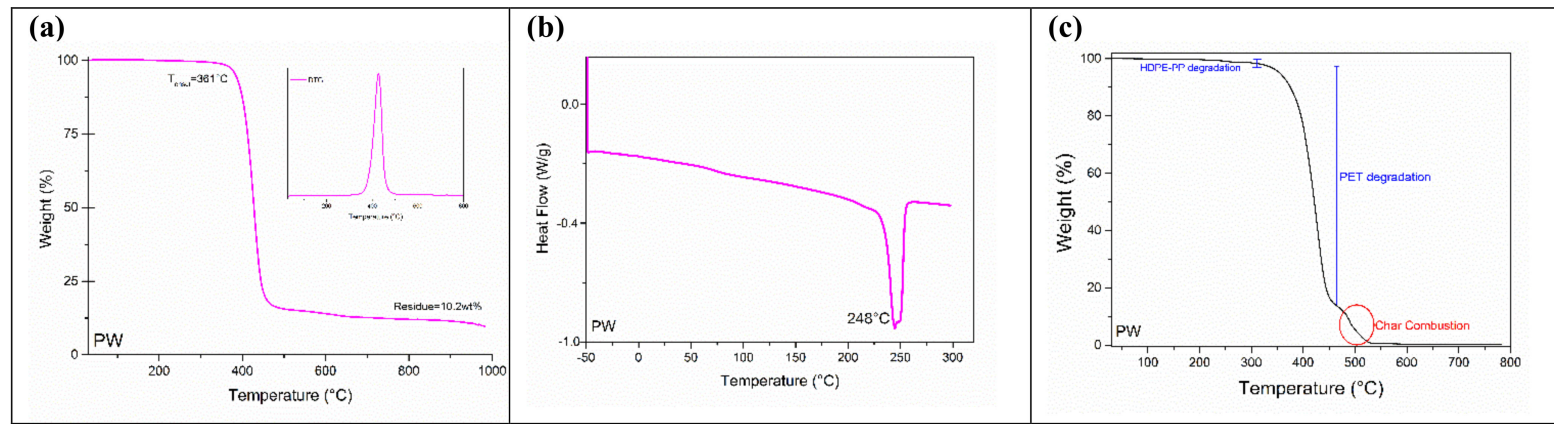

Figure 7. (a) TGA and DTGA in $\mathrm{N}_{2}$ atmosphere, (b) DSC analysis, and (c) TGA in air atmosphere of PW sample.

In Figure 8 the thermograms of the MB, NB, and their derivatives are reported. The DTG (see Figure $8 \mathrm{~b}$ ) was used to identify the point at which weight loss is more evident and to determine: (i) the onset degradation temperature ( $\left.T_{\text {onset }}\right)$, (ii) the maximum decomposition temperature $\left(T_{\max }\right)$, and (iii) the corresponding weight loss as well as (iv) the yield of residual char. The main data are summarized in Table 6. For all the investigated systems, an intense degradation event related to the random break/rupture process and subsequent pyrolysis of the components present in the bitumen samples was observed [62]. The DTG curves (see Figure $8 b$ ), showed that MB has the lowest thermal stability with respect to all the other samples, whereas the NB sample exhibited higher thermal stability with respect to its composites. This is due to the presence of the polymeric waste (PET-HDPE-LDPE-PP) which, with its $T_{\max }$ equal to $427^{\circ} \mathrm{C}$, slightly decreases the $T_{\max }$ value of $\mathrm{NB}$ from $456{ }^{\circ} \mathrm{C}$ to 442,434 , and $435^{\circ} \mathrm{C}$, for the three investigated blends B1, B2, and B3, respectively.

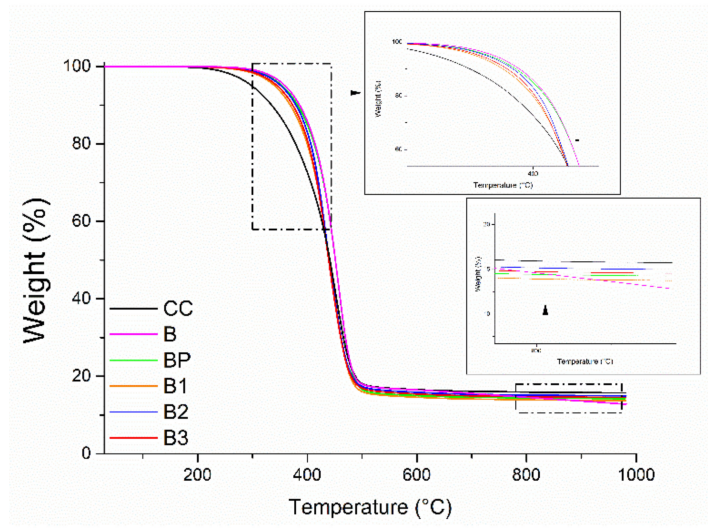

(a)

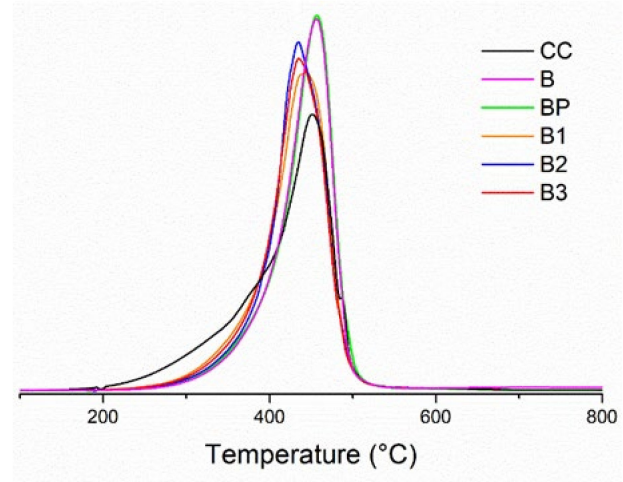

(b)

Figure 8. (a) Thermograms with the inset of two main sections of the graph zoomed in and (b) derivative thermograms of bitumen samples and their composites.

Table 6. Thermal properties of bitumen samples.

\begin{tabular}{ccccc}
\hline Sample & $\boldsymbol{T}_{\text {onset }}\left({ }^{\circ} \mathbf{C}\right)$ & $\boldsymbol{T}_{\text {max }}\left({ }^{\circ} \mathbf{C}\right)$ & Loss Weight (wt \%) & Char (wt\%) \\
\hline PW & 361 & 427 & $90 \%$ & 10.20 \\
MB & 200 & 452 & 84.00 & 16.00 \\
NB & 276 & 456 & 85.75 & 14.25 \\
NBat150 -10 min & 278 & 456 & 87.00 & 13.00 \\
B1 & 275 & 442 & 86.20 & 13.80 \\
B2 & 275 & 434 & 85.00 & 15.00 \\
B3 & 276 & 435 & 85.30 & 14.30 \\
\hline
\end{tabular}

In Figure 9, DSC thermograms of all the investigated samples are reported. $\mathrm{MB}$ and NB samples showed glass transition temperature $\left(T_{g}\right)$ values of $-20^{\circ} \mathrm{C}, 10^{\circ} \mathrm{C}$, and $60^{\circ} \mathrm{C}$ 
which Özdemir et al. [63] associated, respectively, to the saturate, aromatic, and resin components of the bitumen. During the evaluation of possible interactions among the components in the bituminous blend, the obtained DSC results showed that the presence of PW does not bring any significant change in the $T_{g}$ of the composites, whereas some differences can still be observed in the melting temperatures. Indeed, DSC curves revealed two sharp melting peaks $\left(T_{m}=246{ }^{\circ} \mathrm{C}\right.$ and $\left.256{ }^{\circ} \mathrm{C}\right)$ which indicates, as expected, the presence of plastic components in the blend and, particularly, the presence of different types of polymers in the PW including PET whose crystalline melting temperature is about $\sim 260^{\circ} \mathrm{C}$. It is worth noting that the blend of bitumen and $\mathrm{PW}$ is incompatible in nature [63]. They observed that, at low PW content (up to 5\%), the presence of small melting peaks has been observed, indicating some level of compatibility. However, at higher loading content (i.e., $7 \%$ ), two distinct and sharp melting peaks have been observed, thus indicating a high level of incompatibility of polymers in the bituminous matrix. Similar behavior was observed in the DSC curves of the samples investigated in the present work, thus confirming the incompatibility of the blends.

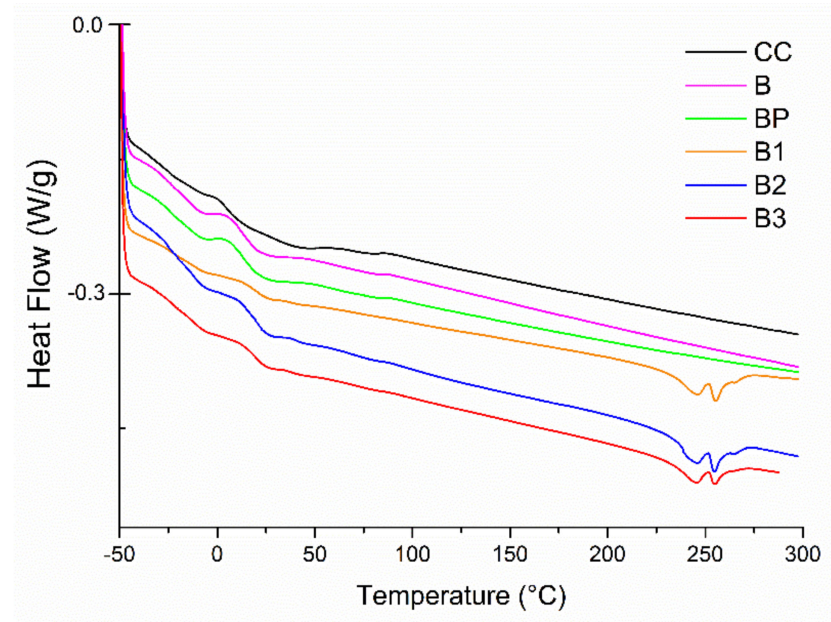

Figure 9. DSC curves of asphalt samples and their composites.

\subsection{Performance Results of Asphalt Binder and Mixtures}

In the first analysis, to evaluate the FS results the master curves have been designed (see Figure 10) [32].

In Figure 10 it can first be observed that the three blends show different behavior as the temperature increases if compared to NB. At low temperatures, the B2 and B3 blends behave in the same way as NB in terms of $\left|G^{*}\right|$, while B1 showed a $47 \%$ higher $\left|G^{*}\right|$ than $\mathrm{NB}$; at high test temperatures, the behavior of $\mathrm{B} 2$ and $\mathrm{B} 3$ is changed, resulting in a $\left|G^{*}\right|$ value respectively 80 and $333 \%$ higher compared to NB.

For test temperatures below $30^{\circ} \mathrm{C}, \mathrm{B} 1$ returned a $\left|\mathrm{G}^{*}\right|$ value on average $77 \%$ higher than that of $\mathrm{NB}$, while for test temperatures above $30^{\circ} \mathrm{C}$, B3 achieved a $\left|G^{*}\right|$ on average $333 \%$ higher than NB.

Comparing the three blends (B1, B2, and B3) it is possible to notice that the complex shear modulus of $\mathrm{B} 1$ for temperatures below $30^{\circ} \mathrm{C}$ is on average 31 and $34 \%$ higher than $\mathrm{B} 2$ and $\mathrm{B} 3$ respectively; at test temperatures above $30^{\circ} \mathrm{C}$ B1 is kept above $\mathrm{B} 2$ on average by $20 \%$, while compared to B3 is reduced of $37 \%$.

In order to identify if the performance of the three blends matched the modified bitumen (MB), a further comparison between $\mathrm{MB}$ and the three blends was carried out. It is noticeable from Figure 10 that $\mathrm{MB}$ returned for test temperatures below $40{ }^{\circ} \mathrm{C}$ a $\left|G^{*}\right|$ value on average $40 \%$ lower than the three asphalt blends, instead for temperatures above $40{ }^{\circ} \mathrm{C}, \mathrm{MB}$ achieved the best performance, in particular $\left|\mathrm{G}^{*}\right|$ is slightly higher of $5 \%$ than B3 that returned the highest $\left|G^{*}\right|$ values for high test temperatures in comparison to the remaining blends with $\mathrm{PW}$ (B1 and $\mathrm{B} 2$ ). 


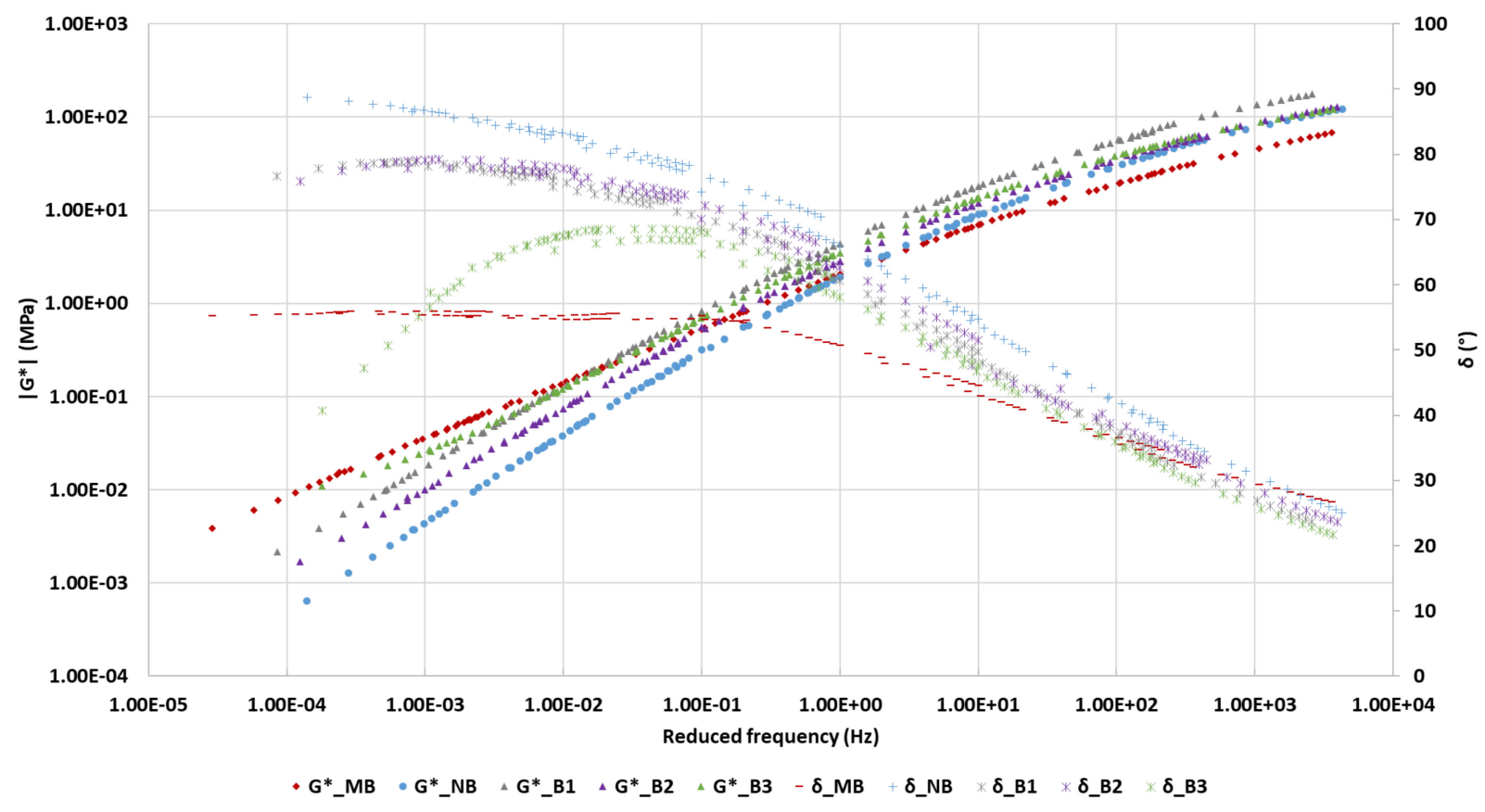

Figure 10. Comparing asphalt blends and binders in terms of master curves.

At high temperatures, the asphalt binders behave like viscous fluids with no capacity for recovering with no viscous component of $\left|G^{*}\right|$, since $\delta=0^{\circ}$. Under normal pavement temperature and traffic loading, bituminous binders act with the characteristics of both viscous liquids and elastic solids; when the binders are loaded, part of their deformation is elastic and part is viscous. Even if two binders are viscoelastic and have the same $\left|G^{*}\right|$, the smaller $\delta$ value establishes which one is more elastic than the other, and the deformation could be recovered much more from an applied load.

Therefore, an analysis of the phase angle was carried out. First of all, as reported in Figure 10, it is noticeable that the phase angles of the three blends are on average $11 \%$ lower than NB; looking in more detail the single blends B1 and B2 returned, in particular, a constant decrease of $8 \%$ regardless of the temperatures, while B3 until $30{ }^{\circ} \mathrm{C}$ is $14 \%$ lower than NB decreasing even more of $19 \%$ and $29 \%$ at 40 and $50{ }^{\circ} \mathrm{C}$, respectively. In this case, it is evident that the elasticity of the blends is given by the amount of PW that for B3 resulted higher than B1 and B2 and it is not dependent on the PW size since B1 and B3 returned the same $\delta$ values.

Comparing the blends with the modified bitumen at $0{ }^{\circ} \mathrm{C}$, the $\delta$ values of $\mathrm{B} 1, \mathrm{~B} 2$, and MB matched, while B3 returned a 9\% lower phase angle values.

Since $30{ }^{\circ} \mathrm{C}$ resulted in a change of behavior for all the solutions so far analyzed, a Cole-Cole diagram at $30^{\circ} \mathrm{C}$ was designed to evaluate in more detail the elastic component in the function of the viscous one (see Figure 11).

The elastic degree of the blends, as is shown in Figure 11, was 10\%, $8 \%$, and $21 \%$ higher than NB for B1, B2, and B3, respectively. The modified bitumen instead, as previously shown by phase angle analysis through the mater curve, returned the highest degree of elasticity between the two bitumen and the three blends.

The measure of the binder's contribution to mixture permanent deformation is calculated through Jnr. The lower value of Jnr confirms the better performance of the asphalt binder sample against permanent deformation. The results reported in Table 7 reveal that by adding the PW the Jnr decreased compared to the neat binder; in fact, taking into account the average at both test temperatures $\left(40\right.$ and $\left.50{ }^{\circ} \mathrm{C}\right)$ and both stress levels $(0.1$ and $3.2 \mathrm{kPa}$ ), overall the Jnr values of the three blends (B1, B2, and B3) are on average $82 \%$ lower than NB. 


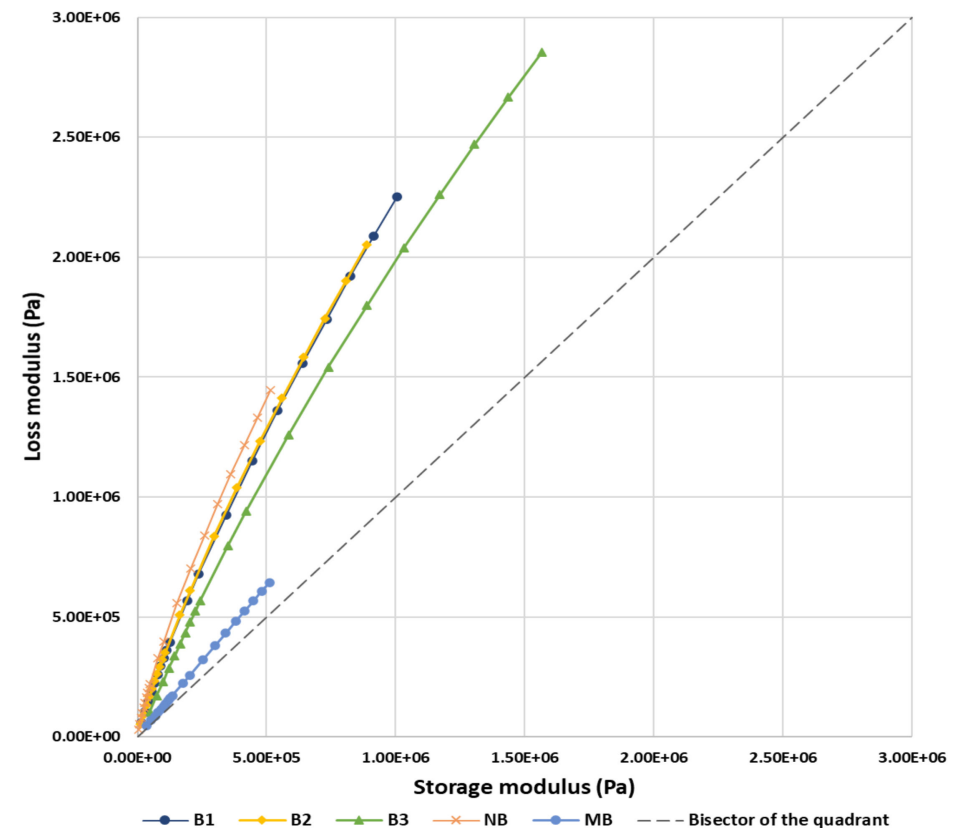

Figure 11. Colę-Cole diagram at $30^{\circ} \mathrm{C}$.

Table 7. MSCR results: Jnr and Jtot both at 40 and $50{ }^{\circ} \mathrm{C}$

\begin{tabular}{|c|c|c|c|c|c|c|c|c|}
\hline \multirow{3}{*}{ Sample } & \multicolumn{4}{|c|}{ Jnr } & \multicolumn{4}{|c|}{ Jtot } \\
\hline & \multicolumn{2}{|c|}{$40^{\circ} \mathrm{C}$} & \multicolumn{2}{|c|}{$50{ }^{\circ} \mathrm{C}$} & \multicolumn{2}{|c|}{$40{ }^{\circ} \mathrm{C}$} & \multicolumn{2}{|c|}{$50{ }^{\circ} \mathrm{C}$} \\
\hline & $0.1 \mathrm{kPa}$ & $3.2 \mathrm{kPa}$ & $0.1 \mathrm{kPa}$ & $3.2 \mathrm{kPa}$ & $0.1 \mathrm{kPa}$ & $3.2 \mathrm{kPa}$ & $0.1 \mathrm{kPa}$ & $3.2 \mathrm{kPa}$ \\
\hline NB & 0.1628 & 0.1722 & 1.1230 & 1.2119 & 0.1647 & 0.1739 & 1.1266 & 1.2125 \\
\hline MB & 0.0115 & 0.0185 & 0.0509 & 0.0787 & 0.0170 & 0.0219 & 0.0639 & 0.0903 \\
\hline B1 & 0.0309 & 0.0493 & 0.1746 & 0.2981 & 0.0342 & 0.0515 & 0.1880 & 0.3030 \\
\hline B2 & 0.0360 & 0.0462 & 0.2403 & 0.3575 & 0.0389 & 0.0484 & 0.2538 & 0.3621 \\
\hline B3 & 0.0051 & 0.0205 & 0.0499 & 0.1204 & 0.0152 & 0.0224 & 0.0614 & 0.1258 \\
\hline
\end{tabular}

Looking into detail at the Jnr value of the three blends at $40{ }^{\circ} \mathrm{C}$, under both 0.1 and $3.2 \mathrm{kPa}, \mathrm{B} 3 \mathrm{was}$ 71\% lower than B1 and B2; at the same time, B1 had a 17\% lower Jnr value with respect to $\mathrm{B} 2$ at $0.1 \mathrm{kPa}$, while no substantial difference occurs between them at $3.2 \mathrm{kPa}$.

At the test temperature of $50{ }^{\circ} \mathrm{C}$, under both stress levels, B3 showed lower Jnr values than B1 and B2, 72\% and 65\%, respectively. Comparing B1 and B2, B1 returned a Jnr value on average $22 \%$ lower.

A further comparison was made with the modified bitumen (MB), that compared to NB returned on average $92 \%$ lower Jnr values. Among all blends, B3 returned $55 \%$ and $2 \%$ lower Jnr value compared to $\mathrm{MB}$ under $0.1 \mathrm{kPa}$ respectively at 40 and $50^{\circ} \mathrm{C}$.

Figure 12 shows two 3D scatter plots where the $x$-axis shows Jtot, the $y$-axis shows $G^{\prime}$, and the $z$-axis shows Jnr at the test temperatures of 40 (see Figure 12a) and $50{ }^{\circ} \mathrm{C}$ (see Figure 12b). These graphs have been plotted to represent in a synthetic way the degree of elasticity of the blends and the binders, better conveyed through a link between the three characteristic parameters (Jnr, Jtot, and $G^{\prime}$ ). As can be observed from the figure, all the asphalt blends exhibit behavior completely different from NB and near $\mathrm{MB}$, both at 40 and $50{ }^{\circ} \mathrm{C}$. B1 and B2 appear to be closer to modified bitumen, otherwise, the deviation of B3 compared to MB seems more marked compared to other mastics, due to the higher $G^{\prime}$ value for B3. Therefore, among all mixtures, B3 is the most elastic, even more so than MB. 


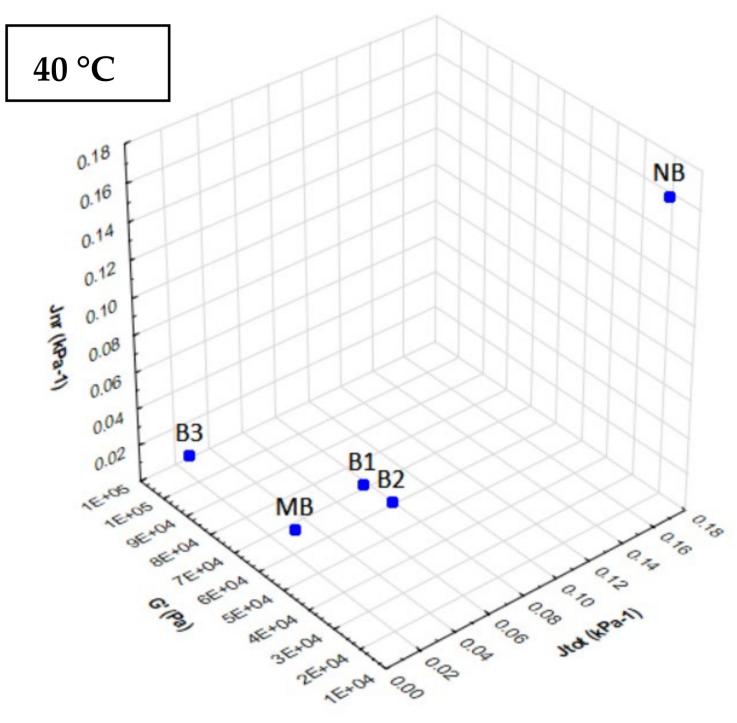

(a)

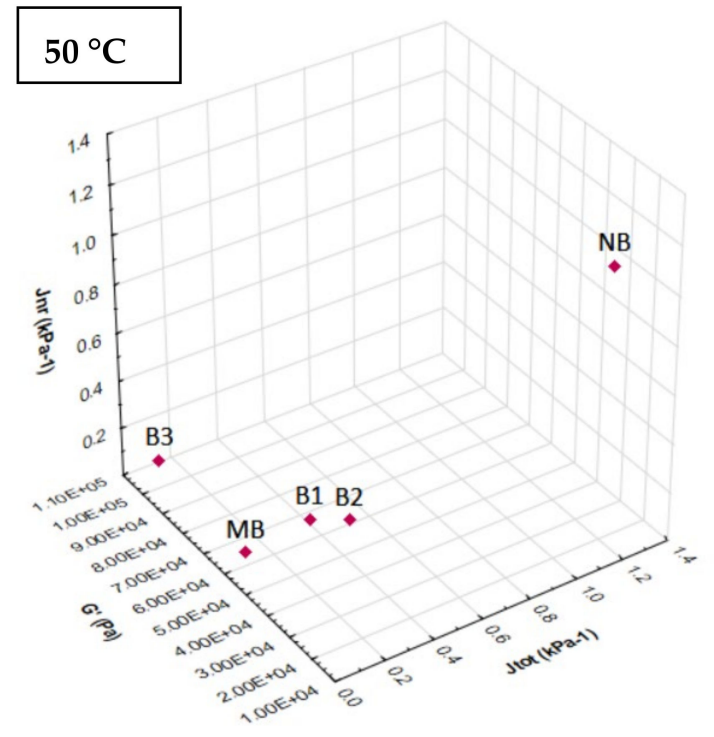

(b)

Figure 12. Scatter plot by comparing Jtot, $G^{\prime}$, and Jnr: (a) $40{ }^{\circ} \mathrm{C}$ and (b) $50{ }^{\circ} \mathrm{C}$.

The data in Table 7 provide an exhaustive characterization of the blends since the Jtot reported were evaluated immediately before load removal. It is evident from the results that no substantial difference returned the three blends between Jnr and Jtot at the same temperature and stress level, confirming their ability to recover deformation already after one second of the end of the creep phase after load removal.

As can be seen from the results above described, B3 returned the most suitable solution to be compared to a modified bitumen as those objects of the present research.

From the investigation carried out on the asphalt mastics, B3 resulted as the most suitable blends to be reemployed into asphalt mixtures. Therefore, an internal laboratory protocol was pursued for mixing the asphalt mixture with the $20 \%$ PW by the weight of $\mathrm{NB}\left(\mathrm{HMA}_{\mathrm{B} 3}\right)$ as follows:

- The aggregates were preheated for $4 \mathrm{~h}$ at $180^{\circ} \mathrm{C}$.

- The PW stored at room temperature was added directly to the aggregates, before the bitumen. The first blending with coarse aggregates, sand, and PW was performed for 2 min to obtain a homogenous dispersion of all $\mathrm{PW}$ particles into the aggregates.

- The next steps involved the addition of the NB, preheated for $1 \mathrm{~h}$ at $150^{\circ} \mathrm{C}$, and further mixing, for approximately $5 \mathrm{~min}$ until the aggregates were fully coated with bitumen.

- The filler was then added, and further mixing was performed for $5 \mathrm{~min}$.

- After the mixing phase, the mixture was put in the oven for $2 \mathrm{~h}$ until it reached a uniform compaction temperature.

Using a Ndes equal to 100 the alternative asphalt mixture, $\mathrm{HMA}_{\mathrm{B} 3}$, did not exhibit the same volumetric properties as $\mathrm{HMA}_{\mathrm{NB}}$, since they differed in the Va values, in particular, $\mathrm{HMA}_{\mathrm{B} 3}$ did not satisfy the Superpave requirement for a Va of $4 \%$ at Ndes. Hence, the number of gyrations used for $\mathrm{HMA}_{\mathrm{B} 3}$ was changed and 120 was found to be the appropriate Ndes. The results of the Superpave optimization for $\mathrm{HMA}_{\mathrm{B} 3}$ are reported in Table 8a. 
Table 8. (a) Superpave optimization: $\mathrm{HMA}_{\mathrm{NB}}$ vs. $\mathrm{HMA}_{\mathrm{B} 3}$ volumetric properties and (b) ITS and ITSM results.

(a)

\begin{tabular}{|c|c|c|c|c|c|}
\hline \multirow{2}{*}{$\begin{array}{l}\text { Asphalt } \\
\text { Mixture }\end{array}$} & $\mathbf{V}_{\mathbf{a}}$ & VMA & VFA & $\% \mathrm{G}_{\mathrm{mm}}$ atNdes & Dust Portion \\
\hline & (\%) & $(\%)$ & $(\%)$ & $(\%)$ & $(-)$ \\
\hline $\mathrm{HMA}_{\mathrm{NB}}$ & 4 & 14.2 & 70.6 & $85.57 \%$ & 1.1 \\
\hline $\mathrm{HMA}_{\mathrm{B} 3}$ & 4 & 14 & 71.8 & $97.64 \%$ & 1.1 \\
\hline \multicolumn{6}{|c|}{ (b) } \\
\hline \multirow{2}{*}{$\begin{array}{l}\text { Asphalt } \\
\text { Mixture }\end{array}$} & \multicolumn{2}{|c|}{ ITS (MPa) } & \multicolumn{3}{|c|}{ ITSM (MPa) } \\
\hline & \multicolumn{2}{|c|}{ at $10^{\circ} \mathrm{C}$} & at $10^{\circ} \mathrm{C}$ & at $20^{\circ} \mathrm{C}$ & at $40^{\circ} \mathrm{C}$ \\
\hline $\mathrm{HMA}_{\mathrm{NB}}$ & \multicolumn{2}{|c|}{3.37} & 14853 & 8120 & 773 \\
\hline $\mathrm{HMA}_{\mathrm{MB}}$ & \multicolumn{2}{|c|}{2.97} & 15391 & 8613 & 1051 \\
\hline $\mathrm{HMA}_{\mathrm{B} 3}$ & \multicolumn{2}{|c|}{4.38} & 16498 & 9582 & 1440 \\
\hline
\end{tabular}

The first mechanical characterization of the asphalt mixtures was carried out through the ITS test, whose results are shown in Table $8 \mathrm{~b}$. $\mathrm{HMA}_{\mathrm{B} 3}$ showed the highest ITS at $10{ }^{\circ} \mathrm{C}$ than the other two mixtures, in particular, it was 47.4 and $30 \%$ higher than that of the $\mathrm{HMA}_{\mathrm{MB}}$ and $\mathrm{HMA}_{\mathrm{NB}}$, respectively. The asphalt mixture made up of $\mathrm{MB}$ revealed the lowest ITS at $10{ }^{\circ} \mathrm{C}(2.97 \mathrm{MPa})$. This is related to the MB used for making the asphalt mixture since no differences existed in terms of the grading curves, volumetric properties, or bitumen concentrations among all the optimized mixtures.

Table $8 \mathrm{~b}$ illustrates the mean ITSM for each of the three asphalt mixtures at 10, 20, and $40{ }^{\circ} \mathrm{C}$. The $\mathrm{HMA}_{\mathrm{B} 3}$ exhibited a higher ITSM at all test temperatures, in particular $+11 \%$ at $10{ }^{\circ} \mathrm{C},+18 \%$ at $20{ }^{\circ} \mathrm{C}$, and $+34 \%$ at $40{ }^{\circ} \mathrm{C}$ compared to $\mathrm{HMA}_{\mathrm{NB}}$. Comparing $\mathrm{HMA}_{\mathrm{B} 3}$ with $\mathrm{HMA}_{\mathrm{MB}}$, a slight increase of $9 \%$ at both 10 and $20^{\circ} \mathrm{C}$ was observed, while at $30{ }^{\circ} \mathrm{C}$ $\mathrm{HMA}_{\mathrm{B} 3}$ turned a higher ITSM value of $37 \%$. Therefore, it emerges that, as the temperature increases, the beneficial effect produced by the plastic increases in terms of the final stiffness of the mixture.

In order to better analyze the effect of the introduction of PW in both asphalt binder and asphalt mixtures, all the parameters analyzed either by the mechanical characterization of the mixtures or by the rheological analysis of the asphalt mastics are summarized in Table 9, as a function of temperature. As it can be seen, for all the parameters analyzed it appears that the best performance is attributable to both asphalt mixtures and the binder containing PW (see the red values in Table 9). The highest stiffness shown by both the binder and the mixture containing PW (via ITSM and $\left|G^{*}\right|$ ) is fully due to the plastic content because through the FTIR analysis it has been demonstrated that the mixing phase does not produce aging phenomena of bitumen that can stiffen it. In addition, this result was also validated by the analysis of the descriptive parameters of the elasticity of the asphalt mixtures and binders through $G^{\prime}, \delta, \mathrm{Jnr}$, and Jtot which returned a higher elasticity in the case of $\mathrm{B} 3$ and $\mathrm{HMA}_{\mathrm{B} 3}$; this is obviously due to the solid presence of $\mathrm{PW}$ as it has emerged from the TGA and DSC analysis that at the mixing temperatures of $150^{\circ} \mathrm{C}$, used in this case study, do not produce degrading phenomena of PW and above all that, not all types of PW reach their melting point. 
Table 9. Summary of the asphalt blends and mixtures results.

\begin{tabular}{|c|c|c|c|c|c|c|c|c|c|}
\hline & \multicolumn{3}{|c|}{$10{ }^{\circ} \mathrm{C}$} & \multicolumn{3}{|c|}{$20^{\circ} \mathrm{C}$} & \multicolumn{3}{|c|}{$40^{\circ} \mathrm{C}$} \\
\hline Asphalt Mixture & $\mathrm{HMA}_{\mathrm{NB}}$ & HMA $_{M B}$ & HMA $_{\mathrm{B} 3}$ & HMA $_{\text {NB }}$ & HMA $_{M B}$ & HMA $_{\mathrm{B} 3}$ & HMA $_{\text {NB }}$ & HMA $_{M B}$ & HMA $_{\mathrm{B} 3}$ \\
\hline ITS (MPa) & 3.370 & 2.970 & 4.380 & n.d. & n.d. & n.d. & n.d. & n.d. & n.d. \\
\hline ITSM (MPa) & 14,853 & 15,391 & 16,498 & 8120 & 8613 & 9582 & 773 & 1051 & 1440 \\
\hline Asphalt Binder & NB & MB & B3 & NB & MB & B3 & NB & MB & B3 \\
\hline$\left|G^{*}\right|(\mathrm{MPa})$ & 20.080 & 13.284 & 25.807 & 3.601 & 3.181 & 5.901 & 0.853 & 0.995 & 0.274 \\
\hline$G^{\prime}(\mathrm{MPa})$ & 14.410 & 10.448 & 20.164 & 1.837 & 2.150 & 3.609 & 0.151 & 0.593 & 0.102 \\
\hline$G^{\prime \prime}(\mathrm{MPa})$ & 13.8541 & 8.170 & 15.931 & 3.084 & 2.339 & 4.647 & 0.839 & 0.799 & 0.254 \\
\hline$\delta\left(^{\circ}\right)$ & 47.935 & 41.675 & 40.003 & 63.776 & 49.514 & 55.954 & 82.031 & 53.398 & 66.808 \\
\hline $\operatorname{Jnr}\left(\mathrm{kPa}^{-1}\right)$ & n.d. & n.d. & n.d. & n.d. & n.d. & n.d. & 0.167 & 0.015 & 0.013 \\
\hline Jtot $\left(\mathrm{kPa}^{-1}\right)$ & n.d. & n.d. & n.d. & n.d. & n.d. & n.d. & 0.169 & 0.019 & 0.019 \\
\hline
\end{tabular}

\section{Conclusions}

In this study, the effect of the different sizes and contents of plastic waste were assessed through the chemical, thermal, and rheological investigation of asphalt blends mixed with PW in comparison with a neat bitumen 50/70 and modified bitumen. The plastic waste was a mixture of different plastic waste types with a prevalence of PET and PE.

The results obtained lead to the following conclusions:

- $\quad$ FTIR results highlight that the presence of PW does not affect the oxidation process of SBS-based bitumen, but significantly improves the aging resistance if compared to results obtained using other fillers such as crumb rubber.

- From the rheological and mechanical investigation, it can be seen that as the temperature increases, there is an increase of the beneficial effect produced by the addition of $\mathrm{PW}$ in both asphalt blends and mixtures.

- A total of $20 \%$ PW by weight of NB with a size range between 4 and $0.063 \mathrm{~mm}$ was found to be the blend that performs better than the modified bitumen since in terms of stiffness and elasticity; particularly, $\mathrm{PW}$ is beneficial to the high temperature achieving lower phase angle and Jnr values (averagely 30\% than the other asphalt solutions investigated).

- The adoption of PW as a modifier of the mixture through the dry method, shown by preliminary study on the mechanical characterization of the optimized asphalt mixture by means of Superpave method, was found to produce an increase of the ITS and ITSM at all test temperature in comparison to the asphalt mixtures made up of $\mathrm{NB}$ and $\mathrm{MB}$, despite all mixtures having the same volumetric properties.

It was discovered that during the mixing phase of $150^{\circ} \mathrm{C}$, no melting temperatures and degradation process have been achieved by PW that increases the overall strength and elasticity of the innovative asphalt blends and mixtures.

Author Contributions: Conceptualization, R.V. and G.G.B.; methodology, R.V., C.O. and F.R.; validation, H.M., S.A.B. and F.R.; investigation, R.V., N.V. and L.V.; data curation, N.V., C.O., G.G.B. and L.V.; writing—original draft preparation, R.V. and L.V.; writing—review and editing, G.G.B. and F.R.; visualization, G.G.B. and F.R.; supervision, H.M., S.A.B. and F.R. All authors have read and agreed to the published version of the manuscript.

Funding: This research was developed within the Projects of National Interest-PRIN 2017 "Stone pavements. History, conservation, valorisation and design" (20174JW7ZL) financed by the Ministry of Education, University and Research (MIUR) of the Italian Government.

Institutional Review Board Statement: Not applicable.

Informed Consent Statement: Not applicable.

Data Availability Statement: The data presented in this study are available on request from the corresponding author. 
Acknowledgments: The Italy/Mozambique Cooperation project Preparation And Characterization of Polyolefin Waste Blends/Bitumen Composites For Flexible Road Pavement funded by FIAM (Fundo para a Investigacao Applicada e Multissectiorial) is kindly acknowledged. The authors are grateful to Mario De Angioletti (CNR-IPCB), Fabio Docimo (CNR-IPCB), Mariarosaria Marcedula, and Alessandra Aldi (CNR-IPCB) for technical support.

Conflicts of Interest: The authors declare no conflict of interest.

\section{References}

1. Oreto, C.; Veropalumbo, R.; Viscione, N.; Biancardo, S.; Russo, F. Investigating the environmental impacts and engineering performance of road asphalt pavement mixtures made up of jet grouting waste and reclaimed asphalt pavement. Environ. Res. 2021, 198, 111277. [CrossRef] [PubMed]

2. Verdolotti, L.; Iucolano, F.; Capasso, I.; Lavorgna, M.; Iannace, S.; Liguori, B. Recycling and recovery of PE-PP-PET-based fiber polymeric wastes as aggregate replacement in lightweight mortar: Evaluation of environmental friendly application. Environ. Prog. Sustain. Energy 2014, 33, 1445-1451. [CrossRef]

3. Schyns, Z.O.; Shaver, M.P. Mechanical recycling of packaging plastics: A review. Macromol. Rapid Commun. 2021, $42,2000415$. [CrossRef] [PubMed]

4. Viscione, N.; Veropalumbo, R.; Oreto, C.; Biancardo, S.A.; Abbondati, F.; Russo, F. Additional procedures for characterizing the performance of recycled polymer modified asphalt mixtures. Measurement 2022, 187, 110238. [CrossRef]

5. Nizamuddin, S.; Jamal, M.; Gravina, R.; Giustozzi, F. Recycled plastic as bitumen modifier: The role of recycled linear low density polyethylene in the modification of physical, chemical and rheological properties of bitumen. J. Clean. Prod. 2020, 266, 121988. [CrossRef]

6. Gupta, A.; Lastra-Gonzalez, P.; Rodriguez-Hernandez, J.; González, M.G.; Castro-Fresno, D. Critical assessment of new polymermodified bitumen for porous asphalt mixtures. Constr. Build. Mater. 2021, 307, 124957. [CrossRef]

7. Hajikarimi, P.; Rahi, M.; Moghadas Nejad, F.; Babaii Ashourabadi, E.; Maniei, S.; MohammadGhasemi, P.; Fini, E.H. Introduction of Polymer Nanocomposites to Bitumen to Enhance its Thermomechanical Properties. J. Transp. Eng. Part B Pavements 2021, 147, 04021020. [CrossRef]

8. Wu, S.; Montalvo, L. Repurposing waste plastics into cleaner asphalt pavement materials: A critical literature review. J. Clean. Prod. 2021, 280, 124355. [CrossRef]

9. Vargas, C.; El Hanandeh, A. Systematic literature review, meta-analysis and artificial neural network modelling of plastic waste addition to bitumen. J. Clean. Prod. 2021, 280, 124369. [CrossRef]

10. Leng, Z.; Sreeram, A.; Padhan, R.K.; Tan, Z. Value-added application of waste PET based additives in bituminous mixtures containing high percentage of reclaimed asphalt pavement (RAP). J. Clean. Prod. 2018, 196, 615-625. [CrossRef]

11. Movilla-Quesada, D.; Raposeiras, A.C.; Silva-Klein, L.T.; Lastra-González, P.; Castro-Fresno, D. Use of plastic scrap in asphalt mixtures added by dry method as a partial substitute for bitumen. Waste Manag. 2019, 87, 751-760. [CrossRef] [PubMed]

12. Arabani, M.; Pedram, M. Laboratory investigation of rutting and fatigue in glassphalt containing waste plastic bottles. Constr. Build. Mater. 2016, 116, 378-383. [CrossRef]

13. Behl, A.; Sharma, G.; Kumar, G. A sustainable approach: Utilization of waste PVC in asphalting of roads. Constr. Build. Mater. 2014, 54, 113-117. [CrossRef]

14. Ho, S.; Church, R.; Klassen, K.; Law, B.; MacLeod, D.; Zanzotto, L. Study of recycled polyethylene materials as asphalt modifiers Can. J. Civ. Eng. 2006, 33, 968-981. [CrossRef]

15. Punith, V.S.; Veeraragavan, A.; Amirkhanian, S.N. Evaluation of reclaimed polyethylene modified asphalt concrete mixtures. Int. J. Pavement Res. Technol. 2011, 4, 1.

16. Bagampadde, U.; Kaddu, D.; Kiggundu, B.M. Evaluation of rheology and moisture susceptibility of asphalt mixtures modified with low density polyethylene. Int. J. Pavement Res. Technol. 2013, 6, 217-224.

17. Sembiring, E.; Rahman, H.; Siswaya, Y.M. Utilization of polypropylene to substitute bitumen for asphalt concrete wearing course. Int. J. GEOMATE 2018, 14, 97-102. [CrossRef]

18. Vila-Cortavitarte, M.; Lastra-González, P.; Calzada-Pérez, M.Á.; Indacoechea-Vega, I. Analysis of the influence of using recycled polystyrene as a substitute for bitumen in the behaviour of asphalt concrete mixtures. J. Clean. Prod. 2018, 170, 1279-1287. [CrossRef]

19. Garcia-Morales, M.; Partal, P.; Navarro, F.J.; Gallegos, C. Effect of waste polymer addition on the rheology of modified bitumen. Fuel 2006, 85, 936-943. [CrossRef]

20. Bulatović, V.O.; Rek, V.; Marković, K.J. Rheological properties and stability of ethylene vinyl acetate polymer-modified bitumen. Polym. Eng. Sci. 2013, 53, 2276-2283. [CrossRef]

21. Singh, M.; Kumar, P.; Maurya, M.R. Effect of aggregate types on the performance of neat and EVA-modified asphalt mixtures. Int. J. Pavement Eng. 2014, 15, 163-173. [CrossRef]

22. Sun, M.; Zheng, M.; Qu, G.; Yuan, K.; Bi, Y.; Wang, J. Performance of polyurethane modified asphalt and its mixtures. Constr. Build. Mater. 2018, 191, 386-397. [CrossRef]

23. Bazmara, B.; Tahersima, M.; Behravan, A. Influence of thermoplastic polyurethane and synthesized polyurethane additive in performance of asphalt pavements. Constr. Build. Mater. 2018, 166, 1-11. [CrossRef] 
24. Xu, C.; Zhang, Z.; Zhao, F.; Liu, F.; Wang, J. Improving the performance of RET modified asphalt with the addition of polyurethane prepolymer (PUP). Constr. Build. Mater. 2019, 206, 560-575. [CrossRef]

25. Colbert, B.W.; You, Z. Properties of modified asphalt binders blended with electronic waste powders. J. Mater. Civ. Eng. 2012, 24, 1261-1267. [CrossRef]

26. Pugsley, A.; Zacharopoulos, A.; Smyth, M.; Mondol, J. Performance evaluation of the senergy polycarbonate and asphalt carbon nanotube solar water heating collectors for building integration. Renew. Energy 2019, 137, 2-9. [CrossRef]

27. Al-Hadidy, A.I. Effect of laboratory aging on moisture susceptibility and resilient modulus of asphalt concrete mixes containing PE and PP polymers. Karbala Int. J. Mod. Sci. 2018, 4, 377-381. [CrossRef]

28. Iqbal, M.; Hussain, A.; Khattak, A.; Ahmad, K. Improving the Aging Resistance of Asphalt by Addition of Polyethylene and Sulphur. Civ. Eng. J. 2020, 6, 1017-1030. [CrossRef]

29. Padhan, R.K.; Sreeram, A. Enhancement of storage stability and rheological properties of polyethylene (PE) modified asphalt using cross linking and reactive polymer based additives. Constr. Build. Mater. 2018, 188, 772-780. [CrossRef]

30. Kakar, M.R.; Mikhailenko, P.; Piao, Z.; Bueno, M.; Poulikakos, L. Analysis of waste polyethylene (PE) and its by-products in asphalt binder. Constr. Build. Mater. 2021, 280, 122492. [CrossRef]

31. Brasileiro, L.L.; Moreno-Navarro, F.; Martínez, R.T.; del Sol-Sánchez, M.; Matos, J.M.E.; del Carmen Rubio-Gámez, M. Study of the feasability of producing modified asphalt bitumens using flakes made from recycled polymers. Constr. Build. Mater. 2019, 208, 269-282. [CrossRef]

32. Veropalumbo, R.; Russo, F.; Viscione, N.; Biancardo, S.A.; Oreto, C. Investigating the rheological properties of hot bituminous mastics made up using plastic waste materials as filler. Constr. Build. Mater. 2021, 270, 121394. [CrossRef]

33. Dalhat, M.A.; Al-Abdul Wahhab, H.I. Performance of recycled plastic waste modified asphalt binder in Saudi Arabia. Int. J. Pavement Eng. 2017, 18, 349-357. [CrossRef]

34. Hu, C.; Lin, W.; Partl, M.; Wang, D.; Yu, H.; Zhang, Z. Waste packaging tape as a novel bitumen modifier for hot-mix asphalt. Constr. Build. Mater. 2018, 193, 23-31. [CrossRef]

35. Merkel, D.R.; Kuang, W.; Malhotra, D.; Petrossian, G.; Zhong, L.; Simmons, K.L.; Zhang, J.; Cosimbescu, L. Waste PET Chemical Processing to Terephthalic Amides and Their Effect on Asphalt Performance. ACS Sustain. Chem. Eng. 2020, 8, 5615-5625. [CrossRef]

36. Moghaddam, T.B.; Karim, M.R.; Soltani, M. Utilization of waste plastic bottles in asphalt mixture. Eng. Sci. Technol. Int. J. 2013, 8, 264-271.

37. Haider, S.; Hafeez, I.; Ullah, R. Sustainable use of waste plastic modifiers to strengthen the adhesion properties of asphalt mixtures. Constr. Build. Mater. 2020, 235, 117496. [CrossRef]

38. European Standard. EN 1427 Bitumen and Bituminous Binders—Determination of the Softening Point_Ring and Ball Method; European Standard: Brussels, Belgium, 2015.

39. European Standard. EN 13702 Bitumen and Bituminous Binders. Determination of Dynamic Viscosity of Bitumen and Bitu-Minous Binders by the Cone and Plate Method; European Standard: Brussels, Belgium, 2018.

40. European Standard. EN 14770. Bitumen and Bituminous Binders-Determination of Complex Shear Modulus and Phase Angle-Dynamic Shear Rheometer (DSR); European Standard: Brussels, Belgium, 2012.

41. European Standard. EN 16659. Bitumen and Bituminous Binders-Multiple Stress Creep and Recovery Test (MSCRT); European Standard: Brussels, Belgium, 2015.

42. European Standard. EN 12697-23. Bituminous Mixtures-Test Methods_Part 23: Determination of the Indirect Tensile Strength of Bituminous Specimens; European Standard: Brussels, Belgium, 2018.

43. European Standard. Bituminous Mixtures-Test Methods_Part 12: Determination of the Water Sensitivity of Bituminous Specimens; European Standard: Brussels, Belgium, 2018.

44. European Standard. EN1426 Bitumen and Bituminous Binders-Determination of Needle Penetration; European Standard: Brussels, Belgium, 2015.

45. Veropalumbo, R.; Russo, F.; Oreto, C.; Biancardo, S.A.; Zhang, W.; Viscione, N. Verifying laboratory measurement of the performance of hot asphalt mastics containing plastic waste. Measurement 2021, 180, 109587. [CrossRef]

46. European Standard. EN 1097-2. Tests for Mechanical and Physical Properties of Aggregates_Part 2: Methods for the Determination of Resistance to Fragmentation; European Standard: Brussels, Belgium, 2018.

47. European Standard. EN 933-4. Test for Geometrical Properties of Aggregates—Part 4: Determination of Particle Shape-Shape Index; European Standard: Brussels, Belgium, 2008.

48. European Standard. EN 933-3. Tests for Geometrical Properties of Aggregates_Part 3: Determination of Particle Shape—Flakiness Index; European Standard: Brussels, Belgium, 2012.

49. European Standard. EN 933-8. Tests for Geometrical Properties of Aggregates_Part 8: Assessment of Fines-Sand Equivalent Test; European Standard: Brussels, Belgium, 2015.

50. European Standard. EN 1097-6. Tests for Mechanical and Physical Properties of Aggregates_Part 6: Determination of Particle Density and Water Absorption; European Standard: Brussels, Belgium, 2013.

51. European Standard. EN 13108-1Bituminous Mixtures-Material Specifications_Part 1: Asphalt Concrete; European Standard: Brussels, Belgium, 2016.

52. Asphalt Institute. Superpave Series No. 2 (SP-02); Asphalt Institute: Lexington, KY, USA, 1996. 
53. Fuller, W.B.; Thompson, S.E. The Laws of Proportioning Concrete. Trans. Am. Soc. Civ. Eng. 1907, 59, 67-143. [CrossRef]

54. Russo, F.; Veropalumbo, R.; Biancardo, S.A.; Oreto, C.; Scherillo, F.; Viscione, N. Reusing Jet Grouting Waste as Filler for Road Asphalt Mixtures of Base Layers. Materials 2021, 14, 3200. [CrossRef] [PubMed]

55. European Standard. EN 12697-31. Bituminous Mixtures-Test Methods_Part 31: Specimen Preparation by Gyratory Compactor; European Standard: Brussels, Belgium, 2019.

56. Stanzione, M.; Russo, V.; Oliviero, M.; Verdolotti, L.; Sorrentino, A.; Di Serio, M.; Tesser, R.; Iannace, S.; Lavorgna, M. Synthesis and characterization of sustainable polyurethane foams based on polyhydroxyls with different terminal groups. Polymer 2018, 149, 149134-149145. [CrossRef]

57. Yan, C.; Huang, W.; Ma, J.; Xu, J.; Lv, Q.; Lin, P. Characterizing the SBS polymer degradation within high content polymer modified asphalt using ATR-FTIR. Constr. Build. Mater. 2020, 233, 117708. [CrossRef]

58. Verdolotti, L.; Di Maio, E.; Lavorgna, M.; Iannace, S. Hydration-induced reinforcement of rigid polyurethane-cement foams: Mechanical and functional properties. J. Mater. Sci. 2012, 47, 6948-6957. [CrossRef]

59. Verdolotti, L.; Lavorgna, M.; Di Maio, E.; Iannace, S. Hydration-induced reinforcement of rigid polyurethaneecement foams: The effect of the co-continuous morphology on the thermal-oxidative stability. Polym. Deg. Stability 2013, 98, 64-72. [CrossRef]

60. Liguori, B.; Iucolano, F.; Capasso, I.; Lavorgna, M.; Verdolotti, L. The effect of recycled plastic aggregate on chemico-physical and functional properties of composite mortars. Mater. Des. 2014, 57, 578-584. [CrossRef]

61. Das, P.; Tiwari, P. Thermal degradation study of waste polyethylene terephthalate (PET) under inert and oxidative environments Thermochim. Acta 2019, 679, 178340. [CrossRef]

62. Naskara, M.; Chakia, T.K.; Reddy, K.S. Effect of waste plastic as modifier on thermal stability and degradation kinetics of bitumen/waste plastics blend. Thermochim. Acta 2010, 509, 128-134. [CrossRef]

63. Özdemir, D.K.; Topal, A.; Gupta, J.; McNally, T. Aging effects on the composition and thermal properties of styrene-butadienestyrene (SBS) modified bitumen. Constr. Build. Mater. 2020, 235, 117450. [CrossRef] 